\title{
Mesoporous Tungsten Trioxide Photoanodes Modified with Nitrogen-Doped Carbon Quantum Dots for Enhanced Oxygen Evolution Photo-Reaction
}

\author{
Mabrook S. Amer ${ }^{1}{ }^{1}$, Prabhakarn Arunachalam ${ }^{1} \oplus$, Abdullah M. Al-Mayouf ${ }^{1}$, Saradh Prasad ${ }^{2}$, \\ Matar N. Alshalwi ${ }^{1}$ and Mohamed A. Ghanem ${ }^{1, *(D)}$ \\ 1 Electrochemical Sciences Research Chair (ESRC), Chemistry Department, College of Science, King Saud \\ University, Riyadh 11451, Saudi Arabia; msamer@ksu.edu.sa (M.S.A.); parunachalam@KSU.EDU.SA (P.A.); \\ amayouf@ksu.edu.sa (A.M.A.-M.); malshalwi@KSU.EDU.SA (M.N.A.) \\ 2 Department of Astronomy and Physics, College of Science, King Saud University, Riyadh 11451, Saudi \\ Arabia; sprasad@KSU.EDU.SA \\ * Correspondence: mghanem@ksu.edu.sa; Tel.: +966-114670405
}

Received: 29 September 2019; Accepted: 18 October 2019; Published: 22 October 2019

\begin{abstract}
Nanostructured photoanodes are attractive materials for hydrogen production via water photo-electrolysis process. This study focused on the incorporation of carbon quantum dots doped with nitrogen as a photosensitizer into mesoporous tungsten trioxide photoanodes $\left(\mathrm{N}-\mathrm{CQD} /\right.$ meso- $\left.\mathrm{WO}_{3}\right)$ using a surfactant self-assembly template approach. The crystal structure, composition, and morphology of pure and N-CQD- modified mesoporous $\mathrm{WO}_{3}$ photoanodes were investigated using scanning electron and transmission microscopy, X-ray diffraction, and X-ray photoelectron spectroscopy. Due to their high surface area, enhanced optical absorption, and charge-carrier separation and transfer, the resulting $\mathrm{N}-\mathrm{CQD} /$ meso- $-\mathrm{WO}_{3}$ photoanodes exhibited a significantly enhanced photocurrent density of $1.45 \mathrm{~mA} \mathrm{~cm}^{-2}$ at $1.23 \mathrm{~V}$ vs. RHE under AM $1.5 \mathrm{G}$ illumination in $0.5 \mathrm{M} \mathrm{Na}_{2} \mathrm{SO}_{4}$ without any co-catalysts or sacrificial reagent, which was about 2.23 times greater than its corresponding pure meso- $\mathrm{WO}_{3}$. Moreover, the oxygen evolution onset potential of the N-CQD/meso- $\mathrm{WO}_{3}$ photoanodes exhibited a negative shift of $95 \mathrm{mV}$, signifying that both the charge-carrier separation and transfer processes were promoted.
\end{abstract}

Keywords: mesoporous; tungsten; trioxide; carbon; quantum; dots; photo-electrochemical; water splitting

\section{Introduction}

Photo-electrochemical (PEC) water splitting is a sustainable technology for the production of hydrogen fuel using water as the hydrogen source [1,2]. During the last decade, semiconductor metal oxide (SMO) photoelectrodes such as $\mathrm{Fe}_{2} \mathrm{O}_{3}$ [3], $\mathrm{TiO}_{2}$ [4], $\mathrm{ZnO}$ [5], and $\mathrm{BiVO}_{4}$ [6] have received considerable interest as favorable catalysts for converting solar energy into hydrogen fuel. Among them, tungsten trioxide $\left(\mathrm{WO}_{3}\right)$ is recognized as a favorable candidate for visible-light assisted water splitting due to its moderately narrow band energy gap $(\mathrm{Eg}=2.6-2.8 \mathrm{eV})$, highly positive valence band energy levels for PEC water oxidation (3.0 V vs. RHE), and good stability against photo-corrosion $[7,8]$. SMO nanostructures with mesoporous architectures are favorable for application as solar water splitting photoanodes because of their distinctive chemical and physical features [8,9]. In particular, their huge specific surface area delivers a higher density of available active sites as well as a greater light absorption depth, both of which lead to improved photocatalytic performance. The syntheses of ordered mesoporous materials are classified as template-free or templating methods. Methods involving sol-gel [10], chemical vapor deposition (CVD) [11], and spray pyrolysis deposition [12] 
mostly produce materials with irregular mesoporous structures and disordered pore morphology. Besides, the hard-templating method produces organized mesoporous materials with highly crystalline framework that replicates the structure of the mesoporous SBA-15 silica, carbon, or cubic KIT-6 silica template $[13,14]$. However, this method has the disadvantages of being expensive and time-consuming and requires complex procedures. Therefore, it is not suitable for mass production applications. Synthetic methods using soft templates based on amphiphilic block copolymers or surfactants are another efficient and useful option for the preparation of mesostructured materials with various morphologies and tunable pore architectures and can be used in large-scale production [15,16]. Triblock copolymer templates, such as Pluronic ${ }^{\circledR}$ F-127 and Pluronic ${ }^{\circledR}$ P123, are commonly employed for the fabrication of mesoporous materials $[17,18]$. Unfortunately, these templates have a short segment chain length and low glass transition temperature $(\mathrm{Tg})$, which results in the creation of mesoporous materials with low crystallinity, amorphous or semi-crystalline channel walls, and uncontrollable pore size, which are not beneficial for solar water splitting devices [19-21].

Consequently, amphiphilic high molecular weight di-block copolymers, such as polyethylene oxide-b-polystyrene (PEO-b-PS), poly(methyl methacrylate) (PMMA), and poly(2-vinyl pyridine)-b-polystyrene (P2VP-b-PS), have recently been employed for the synthesis of mesoporous SMOs [22,23]. In contrast to triblock copolymers, the di-block PEO-b-PS copolymer has the unique properties of strong hydrophobic/hydrophilic segments, a higher glass transition temperature, and abundant $\mathrm{sp}^{2}$ hybridized carbon in the PS segments, which can be in situ converted into rigid amorphous carbon during the crystallization of the framework in an inert atmosphere. Thus, its ordered mesostructured is retained when it is used as a template [23,24]. Moreover, to advance the PEC response of electrodes for water splitting applications, the precious metals loading Ag, Au, Pt, and $\mathrm{Pd}$ [25-27], as well as photosensitizers such as CdS [28], Bi2S3 [29], and CdSe [30], have been widely employed to modify SMO photoanode materials. However, these photosensitizer materials are unstable and are easily oxidized under the operating conditions of PEC anodes, which limit their potential usage in large-scale applications [31]. In contrast, the incorporation of carbon quantum dots (CQDs) and nitrogen-doped CQDs (N-CQDs) into SMO materials as a photosensitizer is considered to be promising, as carbon quantum dots are cost-effective, electrochemically stable, non-toxic, and composed of earth-abundant elements [32]. The CQDs can act as electron donors and acceptors, leading to the creation of hole/electron pairs and thus enhancing the light absorption and photocatalytic performance of the CQDs/SMO composites. Several reports of the incorporation of a CQD photosensitizer into SMOs to produce high-performance photocatalytic photoanodes have been published recently [33-35]. However, CQDs still have low photosensitization efficiency, which limits their utility for advanced practical applications. More recently, Lim and coworkers demonstrated that doping CQDs with heteroatoms such as nitrogen could significantly increase their light-harvesting, tuning band structure, and optical properties, and thus greatly enhance the PEC properties of hybrids, including the doped CQDs [36]. Zhao et al. demonstrated a facial self-assembly route to integrate ultra-small graphitic $\mathrm{N}$-doped pencil nanodots (PND) into a highly ordered $\mathrm{TiO}_{2}$ mesoporous framework [37]. The hybrid catalyst showed high PEC activity and achieved a photocurrent density of $\sim 1.73 \mathrm{~mA} \mathrm{~cm}^{-2}$ at $0.23 \mathrm{~V}$ vs. $\mathrm{Ag} / \mathrm{AgCl}$, which was 183 and $108 \%$ higher than that of the pure $\mathrm{TiO}_{2}$ and undoped $\mathrm{PND}^{-\mathrm{TiO}}{ }_{2}$, respectively. The PEC performance was credited to the enhanced charge transfer rate between the $\mathrm{TiO}_{2}$ frameworks and the modified PNDs through electron donation by the $\mathrm{N}$ atoms. Within this context, hybrid materials combining mesoporous tungsten trioxide $\left(m e s o-\mathrm{WO}_{3}\right)$ and CQDs or N-CQDs have never been reported and could be a favorable candidate for promoting PEC performance for water oxidation. Herein, we reported a facile synthetic route for the fabrication of ordered meso- $\mathrm{WO}_{3}$ via a dip-coating method and evaporation-induced self-assembly (EISA) using tetrahydrofuran (THF) as the solvent and PEO-b-PS as a template, followed by thermal treatment. The produced meso- $\mathrm{WO}_{3}$ thin films were then decorated with various loadings of CQDs and N-CQDs via an impregnation method. The $\mathrm{N}-\mathrm{CQD} /$ meso- $\mathrm{WO}_{3}$ hybrid materials were systematically evaluated for their water oxidation activity under simulated light. Compared with the bare $\mathrm{WO}_{3}$, the $\mathrm{N}-\mathrm{CQD} /$ meso- $\mathrm{WO}_{3}$ hybrid exhibited about 
2.23 times higher oxygen evolution photocurrent density. The enhanced photocatalytic performance might be credited to the promoted photo-response range and highly efficient charge carrier separation.

\section{Materials and Methods}

\subsection{Chemicals and Materials}

Tungsten (VI), hexachloride ( $\mathrm{WCl}_{6} \geq 99.9 \%$ ), and tetrahydrofuran (THF, $\geq 99.5 \%$ ) were acquired from Sigma Aldrich, Missouri, USA. The precursors used for the CQDs and N-CQDs were sucrose $\left(\mathrm{C}_{12} \mathrm{H}_{22} \mathrm{O}_{11}, \geq 99.5 \%\right)$ and melamine $\left(\mathrm{C}_{3} \mathrm{H}_{6} \mathrm{~N}_{6}, \geq 99 \%\right)$, respectively, which were obtained from Aldrich, Missouri, USA. Sodium sulfate $\left(\mathrm{Na}_{2} \mathrm{SO}_{4}, \geq 99 \%\right)$, isopropanol $\left(\mathrm{C}_{3} \mathrm{H}_{8} \mathrm{O}, \geq 99.5 \%\right)$, and acetone $\left(\mathrm{C}_{3} \mathrm{H}_{6} \mathrm{O}\right.$, $\geq 99.5 \%$ ) were purchased from BDH Middle East, Dubai, UAE. The fluorine-doped tin oxide was used as the substrate (FTO, resistivity $=10^{-14} \Omega \cdot \mathrm{cm}^{-2}$, Lanbo Glass Ltd., Hong Kong, China). All reagents were used as received. Ultrapure water purification system of Milli-Q (Millipore, Inc., Darmstadt, Germany) was used to produce the deionized water with a resistivity of $18.2 \mathrm{MOhm} \mathrm{cm}$.

\subsection{Preparation of CQDs, $\mathrm{N}-\mathrm{CQDs}$, and Mesoporous $\mathrm{WO}_{3}$ Hybrid Photoanodes}

The N-doped CQDs were fabricated via a hydrothermal process using sucrose and melamine $\left(\mathrm{C}_{3} \mathrm{H}_{6} \mathrm{~N}_{6}\right)$ as the sources for carbon and nitrogen, respectively. In a typical synthesis, $7 \mathrm{wt} . \%$ of melamine $(0.0565 \mathrm{~g})$ was dispersed in $30 \mathrm{~mL}$ of deionized water under ambient conditions and agitated vigorously using magnetic stirring for $1 \mathrm{~h}$. Afterward, $0.75 \mathrm{~g}$ of sucrose was introduced to the previous transparent mixed solution at ambient temperature and stirred continuously for a further $30 \mathrm{~min}$. Subsequently, the obtained solution was kept in a $40 \mathrm{~mL}$ Teflon-lined autoclave reactor and subjected to thermal heating for $5 \mathrm{~h}$ at $180^{\circ} \mathrm{C}$. Later, the products were collected, washed with water/ethanol, and then subjected to the drying process in an oven at $60^{\circ} \mathrm{C}$. Finally, the produced N-CQDs samples were denoted as N-CQD-x, where $x$ represented the weight percentage of melamine used in the synthesis process $(3,5,7,13$, or $20 \mathrm{wt}$. \%). The CQDs were prepared using a procedure similar to that mentioned above but without melamine. The mesoporous $\mathrm{WO}_{3}\left(\right.$ meso- $\left.-\mathrm{WO}_{3}\right)$ thin films were synthesized according to a self-assembly surfactant template and dip-coating method following the procedure reported by $\mathrm{Li}$ et al. [23]. An amphiphilic di-block copolymer with the composition PEO117-b-PS198 (Mn = $25850 \mathrm{~g} \cdot \mathrm{mol}^{-1}$ ) was prepared using a previously reported procedure [23]. In a typical experiment, PEO117-b-PS198 (2.0 wt. \%, $200 \mathrm{mg}$ ) was first dissolved in $10 \mathrm{~g}$ of THF, $0.6 \mathrm{~g}$ of concentrated $\mathrm{HCl}$ (37 wt. \%) was carefully added slowly, and the subsequent mixture was magnetically stirred for 30 min. Afterward, $\mathrm{WCl}_{6}(0.6 \mathrm{~g})$ was introduced to the template mixture and agitated continuously for $2 \mathrm{~h}$, after which the template mixture became highly viscous. Subsequently, the FTO substrates were pre-cleaned with a water-detergent mixture, isopropanol, and acetone, respectively, and then rinsed with deionized water. The obtained sol-gel solution was coated onto the FTO substrates using a dip-coating method (Xdip-MV1, West Bengal, India) with a $300 \mathrm{~mm} \cdot \mathrm{min}^{-1}$ withdrawal speed to obtain a transparent thin-film substrate as displayed in Figure S5. Afterward, the obtained film was rested horizontally at $25^{\circ} \mathrm{C}$ for $20 \mathrm{~min}$, dried at $40^{\circ} \mathrm{C}$ for $24 \mathrm{~h}$, and then annealed at $100{ }^{\circ} \mathrm{C}$ for $24 \mathrm{~h}$ to form the $\mathrm{WO}_{3}$-surfactant templated films. Subsequently, the coating process was repeated until the desired number of layers (1-13 layers) of mesoporous $\mathrm{WO}_{3}$ had been applied. Afterward, the as-deposited films on the FTO substrate were pyrolyzed using a temperature ramp of $1^{\circ} \mathrm{C} \cdot \mathrm{min}^{-1}$ to reach a final temperature of $350^{\circ} \mathrm{C}$ for $3 \mathrm{~h}$ under a nitrogen atmosphere to decompose the surfactant. The films were cooled to temperature naturally and then annealed at $450{ }^{\circ} \mathrm{C}$ for another $1 \mathrm{~h}$ in the open air to form the mesoporous $\mathrm{WO}_{3}$ catalyst. To load different amounts of $\mathrm{N}-\mathrm{CQDS}$ or CQDs, the meso- $\mathrm{WO}_{3}$ thin films were immersed in $25 \mathrm{~mL}\left(1.5 \mathrm{mg} \cdot \mathrm{mL}^{-1}\right)$ of a N-CQD or CQD solution for 1,3 , or $5 \mathrm{~h}$. Lastly, the resulting $\mathrm{N}-\mathrm{CQD} /$ or $\mathrm{CQD} /$ meso- $\mathrm{WO}_{3}$ hybrids were rinsed with water, subjected to drying process at 70 ${ }^{\circ} \mathrm{C}$ for $6 \mathrm{~h}$, and stored in a desiccator for further characterization. 


\subsection{Material Characterization}

The crystallography and phase data of the fabricated meso- $\mathrm{WO}_{3}$ samples were analyzed using powder X-ray diffraction (XRD, Rigaku Miniflex 600, Rigaku Corporation, Tokyo, Japan). The morphological structure of the fabricated meso- $\mathrm{WO}_{3}$ catalysts was observed using field emission scanning electron microscopy (FE-SEM, JSM-7000F JEOL system, Tokyo, Japan) armed with energy dispersion X-ray spectroscopy (EDS, INCA 400 Oxford, High Wycombe, UK). The mesoporous and fine structure of the hybrids were further examined using high-resolution transmission electron microscopy (HRTEM, JEOL 2100 F, FEI Tecnai G2 F30, Tokyo, Japan). The samples were characterized using Fourier-transform infrared spectroscopy (FTIR, Perkin Elmer GX spectrophotometer, Ohio, USA) and X-ray photoelectron spectroscopy (XPS, Specs SAGE 150, Thermo Fisher Scientific, MA, USA), and room-temperature photoluminescence (PL) spectra were obtained using a spectrofluorophotometer (Perkin Elmer LS55, Ohio, USA). The optical natures of the fabricated catalysts were assessed using a UV-vis-NIR spectrophotometer (Shimadzu UV-2600, MD, USA). The thickness of the composite films was assessed using a Bruker Dektak XT profilemeter (Coventry, UK). Nitrogen adsorption isotherms were obtained by means of NOVA 2200e surface area analyzer (Quantachrome Instruments, Florida, USA).

\subsection{Photoelectrochemical Measurements of the Hybrid Materials}

The PEC characterizations were evaluated through the potentiostat (BioLogic SAS, VSP-0478, Paris, France) electrochemical system in a three-electrode glass cell with a quartz window in $0.5 \mathrm{M}$ $\mathrm{Na}_{2} \mathrm{SO}_{4}$ electrolyte solution ( $\mathrm{pH} \sim 6.8$ ). The modified meso- $\mathrm{WO}_{3}$ deposited on the FTO photoanodes was employed as the working electrode, and the saturated calomel electrode (SCE) and Pt-mesh $(0.5 \times$ $1.0 \mathrm{~cm}^{2}$ ) were employed as the reference and counter electrode, correspondingly. The potential was normalized to the reference hydrogen electrode (RHE) using the equation, $\mathrm{E}_{\mathrm{RHE}}=\mathrm{E}_{\mathrm{SCE}}+0.244 \mathrm{~V}+$ $0.059 \mathrm{pH}$ at $25^{\circ} \mathrm{C}$, where $\mathrm{pH}=14$ for $1.0 \mathrm{M} \mathrm{KOH}$ solution. Linear sweep voltammograms (LSV) were evaluated in the anodic direction in the dark and under illumination. A xenon lamp (300 W, HAL-320, JAPAN) provided with a solar spectrum of air mass 1.5 global (AM 1.5 G) irradiance. AM 1.5 G filter (was engaged as the light source. A Mott-Schottky (M-S) plot was acquired at a frequency of $1 \mathrm{kHz}$ in the dark using an electrochemical impedance analyzer (BioLogic SAS, VSP-0478). Electrochemical impedance spectroscopy (EIS) analysis was performed in the dark and under illumination at an applied bias of $1.0 \mathrm{~V}$ vs. SCE.

\section{Results and Discussion}

\subsection{Characterization of the CQDs and N-CQDs}

The size and microstructure of the as-prepared N-CQDs were investigated using transmission electron microscope (TEM). The TEM micrograph in Figure 1 shows that the N-CQDs were highly dispersed, with a size distribution of 2 to $7 \mathrm{~nm}$ and an average particle size of $4 \mathrm{~nm}$, as shown in the inset particle size histogram. The HRTEM image of a single N-CQD (inset in Figure 1) clearly shows that the as-synthesized N-CQDs exhibited a lattice spacing of $0.21 \mathrm{~nm}$, which corresponds to the d-spacing of the (100) crystal plane of graphite [38]. The surface chemistry and functional groups of the fabricated CQDs and N-CQDs were investigated using FTIR spectroscopy. The FTIR spectra, displayed in Figure S1, reveal that all the CQD and N-CQD samples exhibited a broad peak in the range 3100-3500 $\mathrm{cm}^{-1}$, which showed the existence of $\mathrm{O}-\mathrm{H}$ and $\mathrm{NH}_{2}$ stretching vibrations [38,39]. The peaks at around $2925 \mathrm{~cm}^{-1}$ were credited to the $\mathrm{CH}_{3}$ and $\mathrm{CH}_{2}$ stretching modes, while the peak at 1705 $\mathrm{cm}^{-1}$ was ascribed to $\mathrm{C}=\mathrm{O}$ stretching vibrations, likely associated with the existence of carboxylic acid or amide groups $[38,40]$. The peaks at $1616 \mathrm{~cm}^{-1}$ were assigned to the $\mathrm{N}-\mathrm{H}$ bending vibration, while the peak at $1445 \mathrm{~cm}^{-1}$ corresponded to $\mathrm{C}-\mathrm{N}$ vibrations [40]. Moreover, the bending vibrations of the $\mathrm{C}-\mathrm{O}$ bond and the stretching vibrations peak of the $\mathrm{C}-\mathrm{O}-\mathrm{C}$ bond were observed at 1388 and $1027 \mathrm{~cm}^{-1}$, respectively [41]. Interestingly, as the nitrogen precursor (melamine) content was increased from 7 to 
$20 \%$, the intensity of the $\mathrm{N}-\mathrm{H}$ and $\mathrm{C}-\mathrm{N}$ peaks at $1616 \mathrm{~cm}^{-1}$ and $1445 \mathrm{~cm}^{-1}$ was enhanced, while the opposite trend was observed for the $\mathrm{C}=\mathrm{O}$ peak at $1705 \mathrm{~cm}^{-1}$. This suggests that as the nitrogen content of the N-CQDs was increased, a concurrent decrease in the oxygen content was observed.

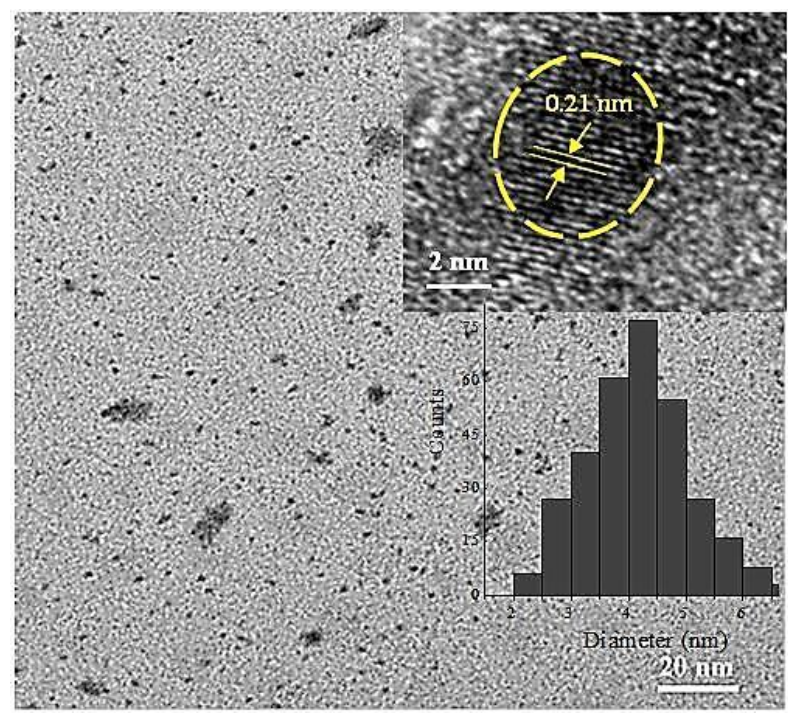

Figure 1. Transmission electron microscopy (TEM) image of the fabricated N-doped carbon quantum dots (7-N-CQDs), insets are the high-resolution TEM (HRTEM) image and its corresponding particle-size distribution histogram of 7-N-CQDs.

The XPS study was carried out to assess the surface states and composition of the CQD and N-CQD samples. As shown in Figure S2a and by comparison to the CQD spectrum, the XPS survey spectrum for N-CQD-7 and N-CQD-20 contains C, N, and O peaks at binding energies of 285, 400, and $531 \mathrm{eV}$, respectively. The XPS spectra revealed that the elemental composition of N-CQD-20 was carbon $(52.3 \%)$, nitrogen $(20.97 \%)$, and oxygen $(26.73 \%)$. These values were very close to those obtained from the EDX elemental analysis displayed in Figure S3. The high-resolution C 1s spectrum of the N-CQD sample displayed in Figure S2b exhibits four main peaks. The peak noticed at $284.05 \mathrm{eV}$ was attributed to the $\mathrm{C}-\mathrm{C}$ bonds of the graphitic structure, suggesting that the graphite structure predominated in the N-CQD sample. The peaks at 286.88, 290.23, and $293.24 \mathrm{eV}$ can be allocated to carbon in the form of $\mathrm{C}-\mathrm{N}, \mathrm{C}-\mathrm{O}$ (sp3), and $\mathrm{C}=\mathrm{O}$, correspondingly [42]. Deconvolution of the $\mathrm{N}$ 1s core spectrum in Figure S2c revealed two main peaks centered at 398.77 and $401.98 \mathrm{eV}$, confirming the presence of nitrogen atoms in pyrrolic- and graphitic-like C-N-C (sp3) and (C)3-N (sp3) structures, correspondingly [42,43]. The O 1s core spectrum of N-CQD-7 in Figure S2d might be deconvoluted into two main peaks at 530.1 $\mathrm{eV}$ and $532.80 \mathrm{eV}$, indicating the existence of $\mathrm{C}=\mathrm{O}$ and $\mathrm{C}-\mathrm{OH}$ or $\mathrm{C}-\mathrm{O}-\mathrm{C}$, respectively [43]. The FTIR and XPS results indicate that the surfaces of the fabricated N-CQDs were functionalized with multiple oxygen and nitrogen groups. More importantly, the data described above confirmed that melamine successfully served as a nitrogen source during the hydrothermal synthetic route of the N-CQDs.

The optical nature of the CQD and N-CQD samples was examined using UV-Vis absorbance and PL spectroscopy as illustrated in Figure S4. UV-Vis spectra of the CQDs and N-CQDs dispersed in water are displayed in Figure S4a. The N-CQDs exhibited a strong UV-vis absorption peak at around $335 \mathrm{~nm}$. This peak originated from the aromatic $n-\pi^{*}$ transition of the $\mathrm{C}=\mathrm{O}, \mathrm{C}-\mathrm{N}$, or $-\mathrm{C}-\mathrm{OH}$ bonds, which may be from hydroxyl $(-\mathrm{COOH})$ or amine $\left(-\mathrm{NH}_{2}\right)$ groups on the surface of the N-CQDs [44]. The inset in Figure S4a shows that the N-CQD dispersion was transparent with a faint yellow color, while under a UV excitation wavelength of $365 \mathrm{~nm}$, it exhibited blue fluorescence, demonstrating the bright luminescence of the prepared N-CQDs. This observation clearly indicated that the N-CQDs had different UV absorption and fluorescence emission behavior than the undoped CQDs. The PL emission spectra of the CQDs, N-CQD-7, and N-CQD-20 in the excitation wavelength range from $340 \mathrm{~nm}$ to 540 
$\mathrm{nm}$, as displayed in Figure S4b-d, respectively. The spectrum of the diluted N-CQD dispersion was dependent on the excitation wavelength, and the emission peaks varied from 440 to $525 \mathrm{~nm}$ under an excitation of 350-540 nm. Furthermore, not only was the fluorescence emission of the prepared N-CQDs stronger than that of the CQD solution of the same concentration, but the maximum fluorescence emission wavelength $\left(\lambda_{\mathrm{em}}\right)$ was also blue-shifted, as displayed in Figure S4c. The fluorescence emission intensity of N-CQD-7 was 9.7 times stronger than that of CQD, which could be explained by a reduction in the number of non-radiative recombination centers on the N-CQD surface [44]. Interestingly, the PL intensity of the N-CQDs under UV excitation improved considerably as the N doping level was increased, as shown in Figure S4e. The N-CQDs with 7\% N displayed the uppermost PL intensity among all the samples. In particular, the strongest emission band was positioned at $533.4 \mathrm{~nm}$ under $480 \mathrm{~nm}$ excitation. Further, the PL emission of the N-CQDs shifted to higher wavelength as its intensity increased. This behavior was attributed to the surface defect emission derived from the CQDs and was inconsistent with previous reports in the literature [45]. The external quantum yields (EQY) of the $\mathrm{N}-C Q D s$ under $360 \mathrm{~nm}$ excitation were assessed using quinine sulfate (QS) as the calibration standard sample. As displayed in Figure S4e, N-CQD-7 revealed a greater EQY of 74.3\%, which was superior to that of N-CQD-20 (60.4\%), N-CQD-13 (33.2\%), N-CQD-5 (18.4\%), and N-CQD-3 (13.4\%). This high PL EQY was mostly due to the attendance of $\mathrm{O}$ and $\mathrm{N}$ atoms. In particular, the heteroatoms in the CQD lattice could reduce the $\pi$-connections between the $\mathrm{sp}^{2}$-domains of carbon atoms, changing their electronic structure and thus suppressing non-radiative energy dissipation [42]. Significantly, increasing the N-doping level in the N-CQDs increased the photoexcitation efficiency, that is, fewer photo-induced electrons in the N-CQDs were quenched by energy traps. Thus, among the various N-CQDs studied, N-CQD-7 exhibited the best photosensitization performance for PEC applications. Thus, CQDs and N-CQD-7 were combined with the meso- $\mathrm{WO}_{3}$ photoanodes as photosensitizers for PEC water oxidation.

\subsection{Characterization of $\mathrm{Meso}-\mathrm{WO}_{3}$ and the $\mathrm{CQD} / \mathrm{Meso}-\mathrm{WO}_{3}$ and $\mathrm{N}-\mathrm{CQD} / \mathrm{Meso}-\mathrm{WO}_{3} \mathrm{Hybrids}$}

The morphology and mesostructure of the mesoporous tungsten trioxide modified with N-CQDs were examined using field emission scanning electron microscopy (FESEM) and HRTEM. The FESEM images of the attained meso- $\mathrm{WO}_{3}$ electrodes are displayed in Figure 2. In particular, the meso- $\mathrm{WO}_{3}$ catalyst annealed at $350{ }^{\circ} \mathrm{C}$ in $\mathrm{N}_{2}$ for $3 \mathrm{~h}$ (see Figure 2a) and then at $450{ }^{\circ} \mathrm{C}$ in air for $1 \mathrm{~h}$ (see Figure 2b) clearly exhibited a well-defined and interconnected mesoporous framework that extended over a very large domain. The FESEM images revealed that the mesoporous morphology of the catalyst did not change during annealing in $\mathrm{N}_{2}$ and air, which confirmed the successful creation of the $\mathrm{WO}_{3}$ mesoporous structure. This can be explained by the fact that the residual carbon can maintain the tungsten oxide mesostructures and prevent wall expansion during annealing in air after burning the surfactant in an $\mathrm{N}_{2}$ atmosphere.

The residual carbon was then removed after annealing in air, leaving the high-surface-area $\mathrm{WO}_{3}$ mesoporous structure. However, as shown in Figure 2c, direct one-step annealing in air at $450{ }^{\circ} \mathrm{C}$ for $2 \mathrm{~h}$ led to the destruction of the mesostructures and the formation of adjoining $\mathrm{WO}_{3}$ particles with a mean particle size of $40 \mathrm{~nm}$. One-step direct calcination in the air caused the concurrent removal of carbon and $\mathrm{WO}_{3}$ nanoparticle growth, which destroyed the mesoporous structure. The FESEM image of the $\mathrm{WO}_{3}$, fabricated in the absence of a surfactant $\left(\right.$ bulk- $\left.\mathrm{WO}_{3}\right)$ in Figure $2 \mathrm{~d}$, does not exhibit any obvious pores, and the surface morphology of the bulk- $\mathrm{WO}_{3}$ consisted of an aggregated nanoparticle structure with a mean particle size of $20 \mathrm{~nm}$. It worth noting that the surface area of the bulk- $\mathrm{WO}_{3} \mathrm{was}$ $18 \mathrm{~m}^{2} \cdot \mathrm{g}^{-1}$, which was significantly less than that of meso- $\mathrm{WO}_{3}$, as confirmed by the sorption isotherm results shown below.

Figure 3 displays the HRTEM images of the meso- $\mathrm{WO}_{3}$ and the modified N-CQD-7/meso- $\mathrm{WO}_{3}$ catalysts. The HRTEM image displayed in Figure 3a reveals that the fine structure of the meso- $\mathrm{WO}_{3}$ catalyst exhibited distinct mesopores arranged in a highly ordered 2D hexagonal mesostructure, with an average pore size of $\sim 5 \mathrm{~nm}$. Furthermore, the higher resolution TEM image in Figure $3 \mathrm{~b}$ displays that 
the meso- $\mathrm{WO}_{3}$ framework consisted of well-crystallized walls with a lattice spacing of $0.265 \mathrm{~nm}$ and $0.382 \mathrm{~nm}$, corresponding to the (200) and (020) diffraction planes of $\mathrm{WO}_{3}$ (JCPDS \# 43-1305).

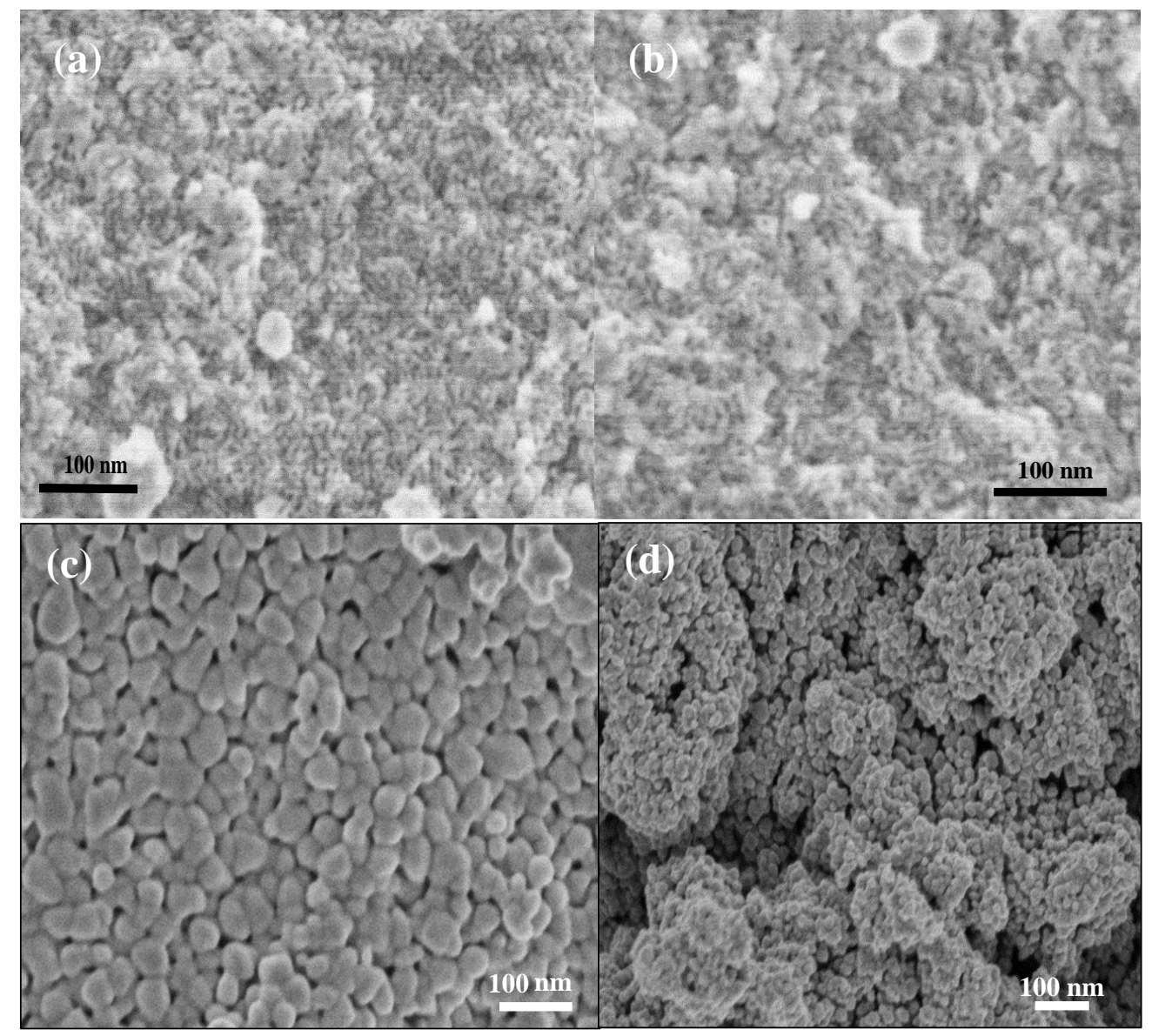

Figure 2. Field emission scanning electron (FESEM) images of (a) meso- $\mathrm{WO}_{3}$ catalyst after annealed at $350{ }^{\circ} \mathrm{C}$ in the $\mathrm{N}_{2}$ atmosphere for $3 \mathrm{~h} \mathrm{(b)} \mathrm{meso-} \mathrm{WO}_{3}$ catalyst after the second step of annealing in air at $450{ }^{\circ} \mathrm{C}$ for $1 \mathrm{~h}$. (c) $\mathrm{WO}_{3}$ annealed in one step at $450{ }^{\circ} \mathrm{C}$ in air (d) bulk- $\mathrm{WO}_{3}$ prepared under similar condition but in absence of PEO-PS template.

Figure $3 \mathrm{c}$ shows the TEM image of the modified N-CQD-7/meso- $\mathrm{WO}_{3}$ catalyst. The N-CQDs (dark spots) were attached to the surface of meso- $\mathrm{WO}_{3}$ (yellow circles) and the mesostructures of the meso- $\mathrm{WO}_{3}$ substrate remained unchanged, demonstrating the successful loading of the N-CQDs on the surface of meso- $\mathrm{WO}_{3}$. The HRTEM image in Figure 3d evidently shows the (100) and (020) lattice fringes with a spacing of 0.21 and $0.382 \mathrm{~nm}$, agreeing to the $\mathrm{N}-\mathrm{CQDs}$ and $\mathrm{WO}_{3}$, respectively. Figure $4 \mathrm{a}$ reveals the $\mathrm{N}_{2}$ sorption isotherms of the meso- $\mathrm{WO}_{3}$ electrodes annealed under different annealing conditions, which exhibited type-IV curves with an $\mathrm{H}_{2}$-type hysteresis loop. For the meso- $\mathrm{WO}_{3}$ sample, the distinct capillary condensation step at a relative pressure of $\mathrm{P} / \mathrm{Po} \sim 0.45$ to 0.80 indicated the uniform mesoporosity of the material. Another sharp $\mathrm{N}_{2}$ uptake with an $\mathrm{H}_{2}$-hysteresis loop at a higher relative pressure of $\mathrm{P} / \mathrm{P} 0>0.85$ reflected the structural defects formed via pyrolysis. In contrast, the bulk- $\mathrm{WO}_{3}$ showed typical sorption isotherms resulting from the aggregation of the nanoparticles. Figure $4 \mathrm{~b}$ shows the pore size distributions of the meso- $\mathrm{WO}_{3}$ electrodes calculated from the adsorption branch via Barrett-Joyner-Halenda (BJH) method, in which a uniform pore size of around $5 \mathrm{~nm}$ was observed. The detail of the textural properties of the meso- $\mathrm{WO}_{3}$ and bulk-WO 3 are reported in Table S1. Clearly, the calculated Brunauer-Emmett-Teller (BET) surface area of the meso- $\mathrm{WO}_{3}$ was $105 \mathrm{~m}^{2} \cdot \mathrm{g}^{-1}$, which was higher than that obtained for bulk- $\mathrm{WO}_{3}\left(18 \mathrm{~m}^{2} \cdot \mathrm{g}^{-1}\right)$ and meso- $\mathrm{WO}_{3}$ directly annealed in air at $450{ }^{\circ} \mathrm{C}$ $\left(28 \mathrm{~m}^{2} \cdot \mathrm{g}^{-1}\right)$. Moreover, the high surface area, open porous structure, and uniform pore size of the 
meso- $\mathrm{WO}_{3}$ materials can be exploited for loading co-catalysts onto their surfaces, making them an ideal electrode material for various energy-related applications such as water splitting devices, solar cells, and batteries.
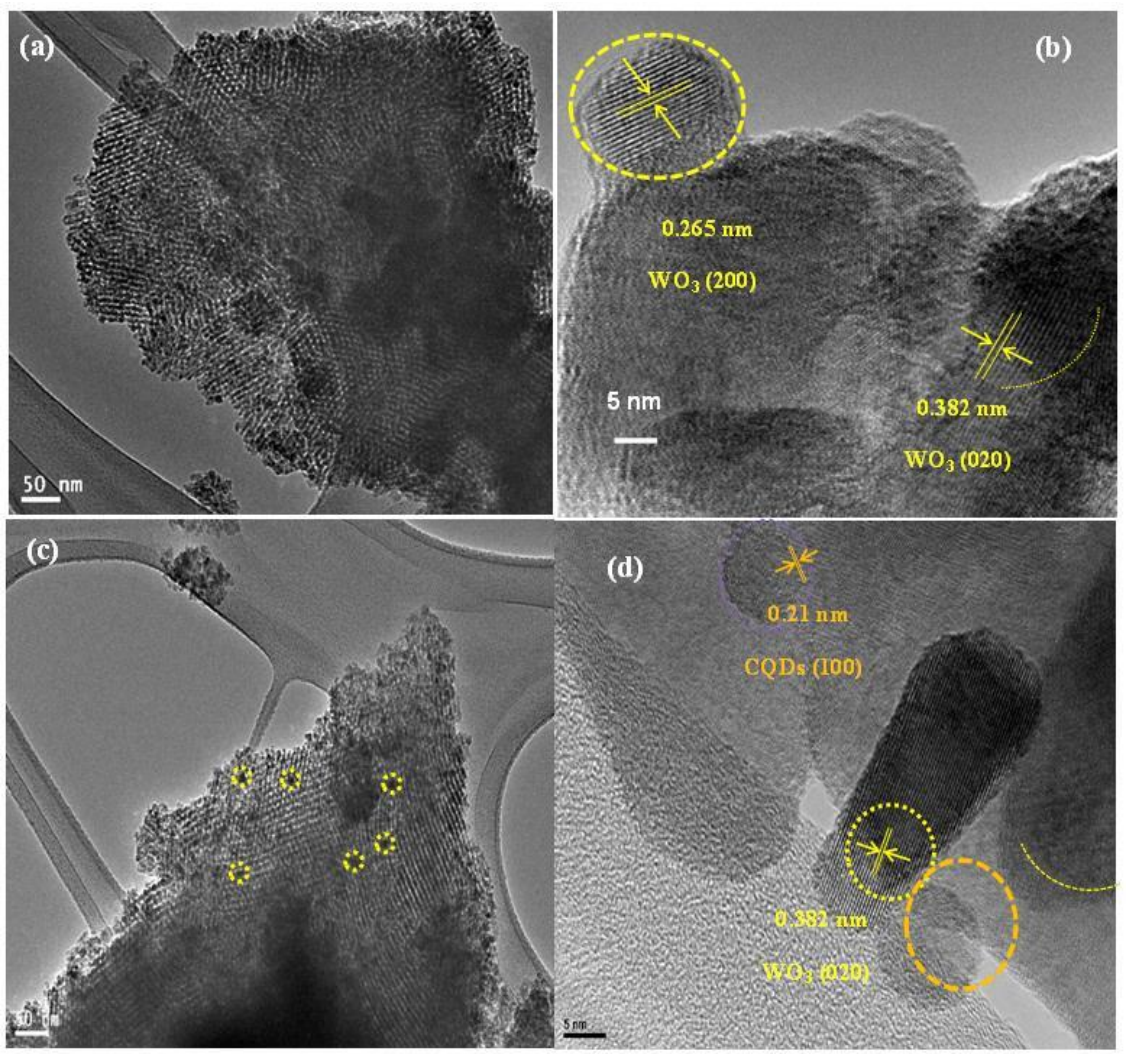

(d)

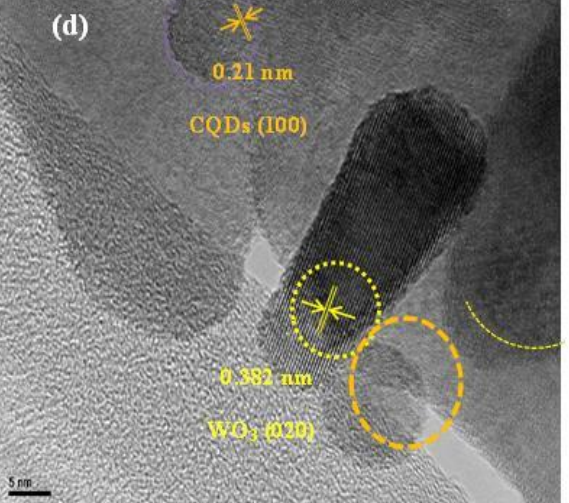

Figure 3. HRTEM images of (a) meso- $\mathrm{WO}_{3}$ (b) 7-N-CQDs $/$ meso- $\mathrm{WO}_{3}$ sample, and a higher magnified HRTEM images of (c) meso- $\mathrm{WO}_{3}$, (d) $7-\mathrm{N}-\mathrm{CQD} /$ meso- $-\mathrm{WO}_{3}$ after annealing at $350{ }^{\circ} \mathrm{C}$ in $\mathrm{N}_{2}$ and $450{ }^{\circ} \mathrm{C}$ in air.
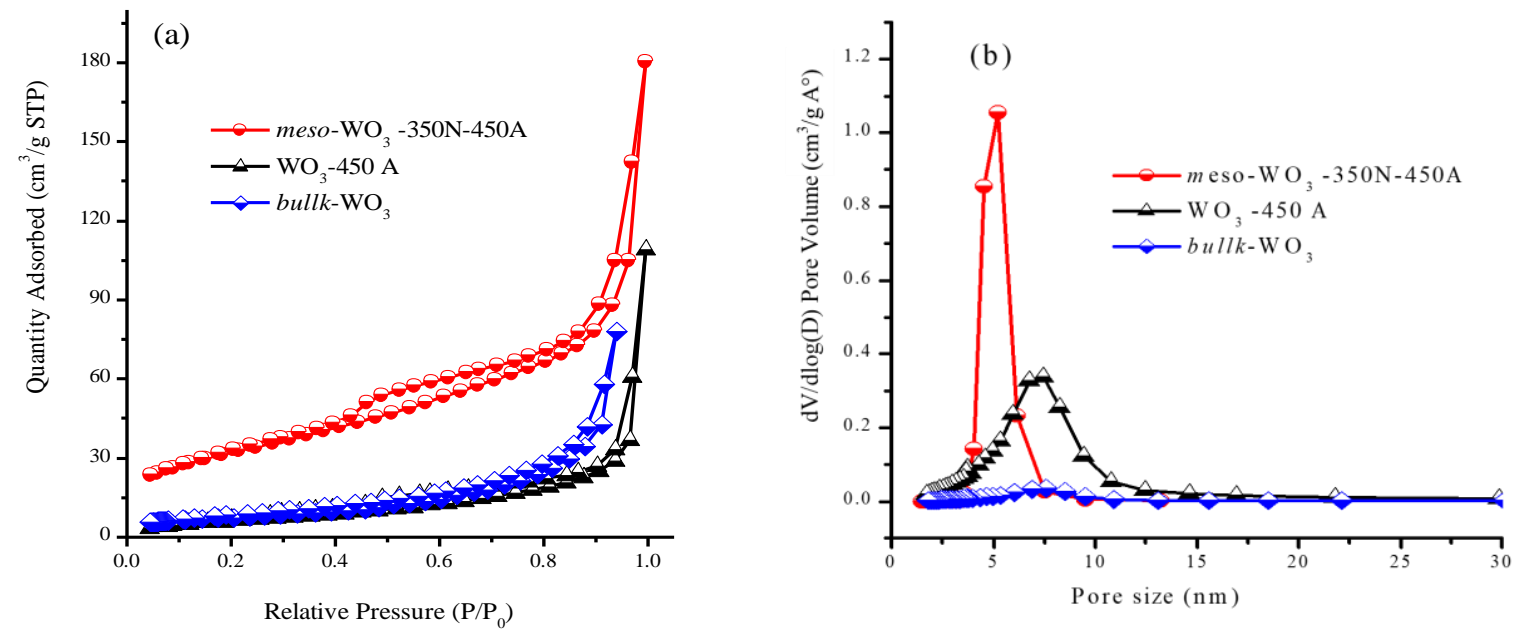

Figure 4. (a) N2 sorption isotherms and (b) Barrett, Joyner, and Halenda (BJH) pore size distributions of meso- $\mathrm{WO}_{3}$ and bulk- $\mathrm{WO}_{3}$ samples.

As displayed in Figure S5, the meso- $\mathrm{WO}_{3}$ photoanodes were modified with CQD and N-CQD by dipping the meso- $\mathrm{WO}_{3} / \mathrm{FTO}$ photoanodes in the CQD solutions for different lengths of time after the annealing steps. The meso- $\mathrm{WO}_{3} / \mathrm{FTO}$ showed a light red color after being dipped in the CQD solution for $5 \mathrm{~h}$, indicating the successful deposition of the CQDs onto the surface of $\mathrm{WO}_{3}$ (Figure S5, SI). 
Figure 5 reveals the diffraction patterns of the pure meso- $\mathrm{WO}_{3}, \mathrm{CQD} /$ meso- $-\mathrm{WO}_{3}$, and N-CQD/meso- $\mathrm{WO}_{3}$ photoanodes. The diffraction peaks of pure meso- $\mathrm{WO}_{3}$ might be well-indexed to the planes of monoclinic $\mathrm{WO}_{3}$ (JCPDS No.01-072-0677), confirming the successful synthesis of meso- $\mathrm{WO}_{3}$. The $\mathrm{XRD}$ peaks of $\mathrm{CQD} /$ meso- $\mathrm{WO}_{3}$ and $\mathrm{N}-\mathrm{CQD} /$ meso- $\mathrm{WO}_{3}$ were consistent with those of pure meso- $\mathrm{WO}_{3}$, indicating that the addition of the N-CQDs did not alter the crystalline phase of meso- $\mathrm{WO}_{3}$. The XRD peaks of the CQDs and N-CQDs could not be resolved in the $\mathrm{CQD} /$ meso- $-\mathrm{WO}_{3}$ and $\mathrm{N}-\mathrm{CQD} /$ meso- $\mathrm{WO} \mathrm{O}_{3}$ composites, possibly due to the low loading amount and dispersion of the CQDs, which was consistent with the literature [42].

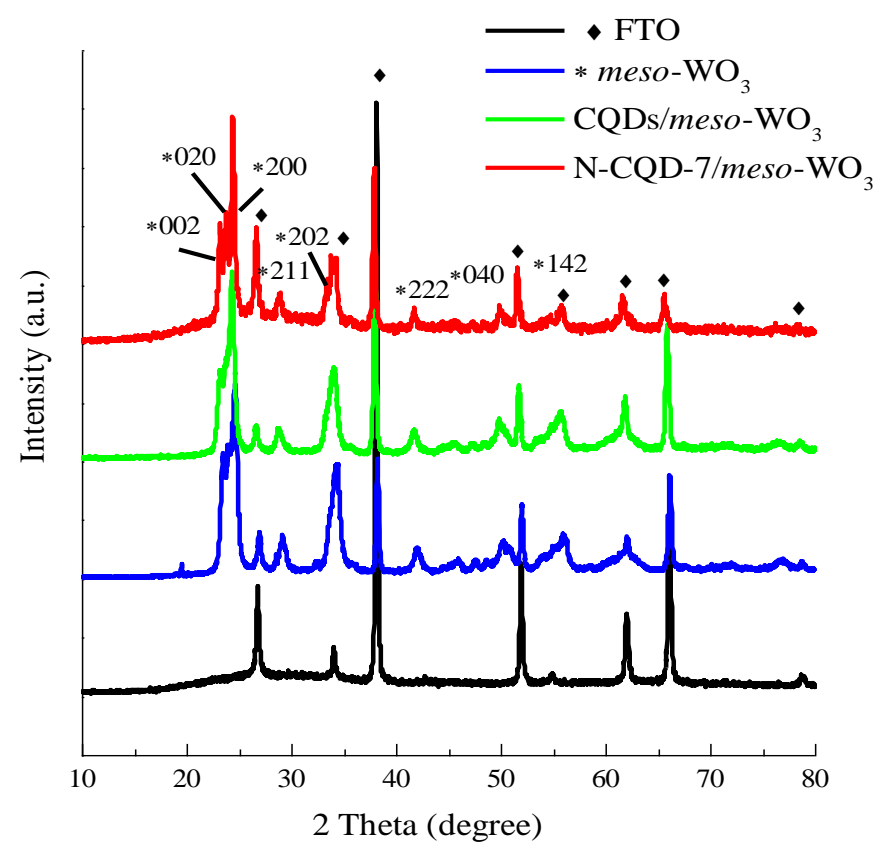

Figure 5. XRD patterns of $m e s o-\mathrm{WO}_{3}, \mathrm{CQDs} /$ meso- $\mathrm{WO}_{3}$ and $\mathrm{N}$-doped CQDs/meso- $\mathrm{WO}_{3}$ composites.

The N-CQD-7/meso- $\mathrm{WO}_{3}$ electrode was examined using XPS analysis as displayed in Figure 6. The XPS wide survey spectrum of $\mathrm{N}-\mathrm{CQD} / \mathrm{meso}-\mathrm{WO}_{3}$ in Figure 6a indicated the attendance of the elements $\mathrm{W}, \mathrm{O}, \mathrm{C}$, and $\mathrm{N}$ at the surface of the photoanode. In Figure $6 \mathrm{~b}$, the core spectrum of $\mathrm{W} 4 \mathrm{f}$ shows two well-resolved peaks at 36.25 and $38.40 \mathrm{eV}$, which were assigned to the $\mathrm{W} 4 \mathrm{f}_{7 / 2}$ and $\mathrm{W} 2 \mathrm{f}_{3 / 2}$ orbital signals. Moreover, the narrow $\mathrm{O} 1 \mathrm{~s}$ peak in Figure $6 \mathrm{c}$ can be deconvoluted to three peaks appearing at binding energies of $528.77,530.90$, and $531.61 \mathrm{eV}$, corresponding to the lattice oxygen of the layer-structured $\mathrm{WO}_{3}$ and adsorbed $\mathrm{H}_{2} \mathrm{O}$ or surface hydroxyl oxygen, correspondingly [15]. The $\mathrm{C}$ 1s high-resolution spectrum in Figure 6d contains three different contributions at 284.90, 286.28, and $288.63 \mathrm{eV}$, which were related to carbon in the $\mathrm{C}-\mathrm{C}, \mathrm{C}-\mathrm{O}$, and $\mathrm{C}=\mathrm{N} / \mathrm{C}=\mathrm{O}$ states, respectively [15-42]. The high-resolution $\mathrm{N} 1 \mathrm{~s}$ spectrum in Figure 6e exhibits two peaks centered at 398.70 and $402.0 \mathrm{eV}$, which were credited to the $\mathrm{C}-\mathrm{N}-\mathrm{C}$ and $(\mathrm{C})_{3}-\mathrm{N}$ bonds $[43,44]$, confirming that the surface of the $\mathrm{N}-\mathrm{CQD} /$ meso- $\mathrm{WO}_{3}$ was rich in nitrogen-containing functional groups. Thus, the $\mathrm{C} 1 \mathrm{~s}, \mathrm{O} 1 \mathrm{~s}$, and $\mathrm{N} 1 \mathrm{~s}$ spectra further demonstrated that the N-CQDs were loaded to the surface of the meso- $\mathrm{WO}_{3}$ substrate and that the $\mathrm{N}-\mathrm{CQD} /$ meso- $\mathrm{WO}_{3}$ composites had successfully been fabricated. 

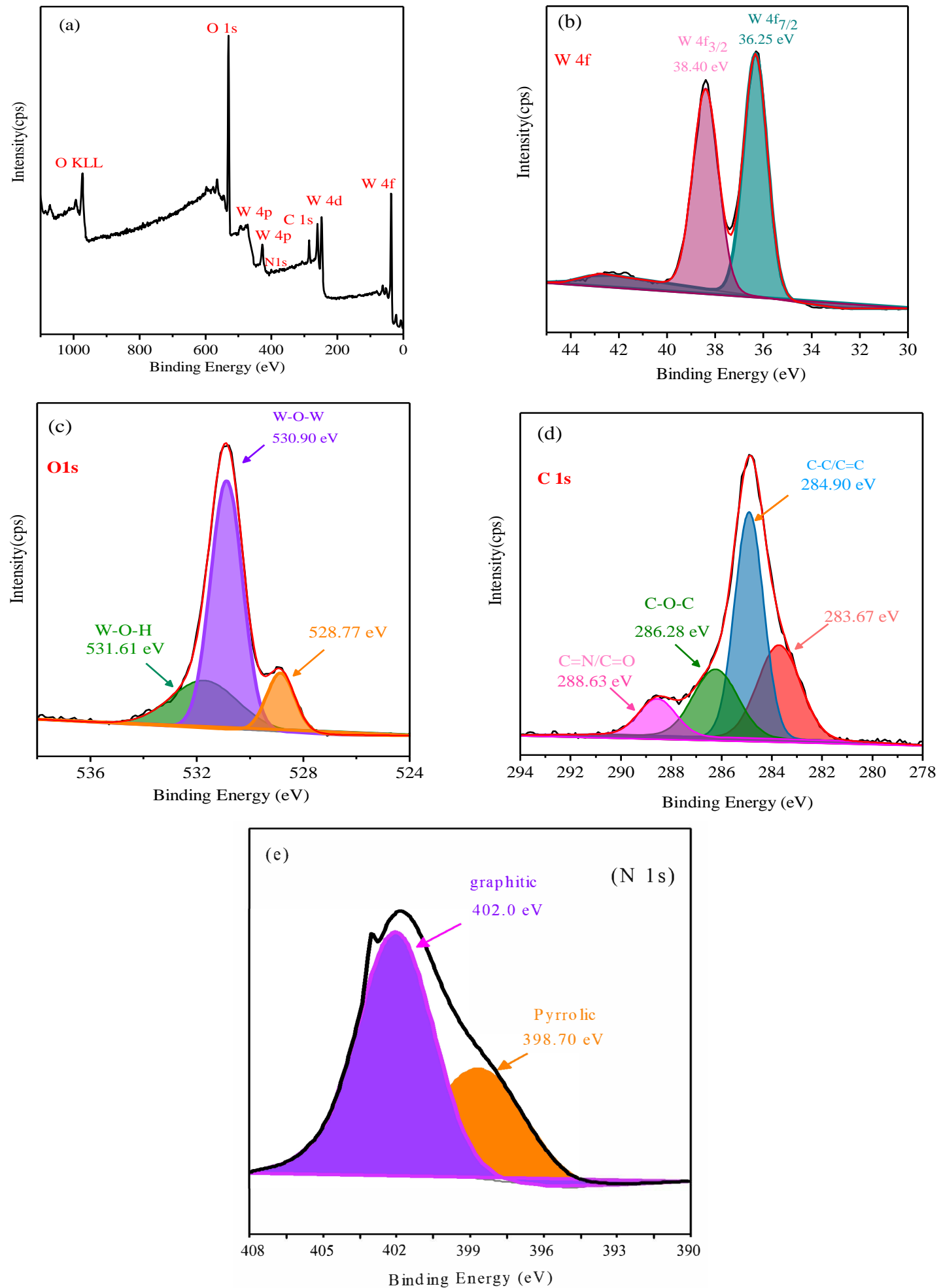

Figure 6. XPS spectra of as-synthesized N-CQDs/meso-WO $\mathrm{WO}_{3}$ composite, (a) survey, (b) W 4f, (c) O 1S, (d) C 1s, and (e) N 1s core spectrum.

To examine the effect of the CQD and N-CQD doping on the light-harvesting capability of meso- $\mathrm{WO}_{3}$, the optical properties of meso- $\mathrm{WO}_{3}$ and the $\mathrm{CQD}$ and $\mathrm{N}-\mathrm{CQD} /$ meso- $\mathrm{WO}_{3}$ photoanodes were investigated using UV-vis absorption. As depicted in Figure 7a, the meso- $\mathrm{WO}_{3}$ photoanodes exhibited optical absorption in the range of $300-473 \mathrm{~nm}$, and the absorption spectrum capacity in the visible-light region was significantly enriched by the addition of N-CQDs. Figure $7 \mathrm{~b}$ displays the Tauc plots of 
the meso- $\mathrm{WO}_{3}$ and $\mathrm{N}-\mathrm{CQD} /$ meso- $\mathrm{WO}_{3}$ composite films. The band gaps of the composite films were evaluated by plotting $(\alpha \mathrm{h} v) 1 / 2$ against the photon energy [46]. The plot of $(\alpha \mathrm{h} v) 1 / 2$ vs. the photon energy $(\mathrm{h} v)$, displayed in Figure $7 \mathrm{~b}$, was used to evaluate the bandgap energies of the meso-WO3 and $\mathrm{N}-\mathrm{CQD}-7 /$ meso- $\mathrm{WO}_{3}$ photoanodes. The bandgap of the pristine meso- $\mathrm{WO}_{3}$ photoanode was around $2.70 \mathrm{eV}$, while that of the N-CQD-7/meso- $\mathrm{WO}_{3}$ photoanode was $2.63 \mathrm{eV}$. Moreover, the conduction band (CB) and valence band (VB) of the meso- $\mathrm{WO}_{3}$ and N-CQD-7/meso- $\mathrm{WO}_{3}$ photoanodes were assessed using the following equation [47]:

$$
E_{C B}=x-E_{e}+0.5 E_{g} ; E_{V B}=E_{C B}+E_{g}
$$

where $\chi$ represents the absolute electronegativity of the semiconductor, with the $\chi$ value of $\mathrm{WO}_{3}$ being $6.59 \mathrm{eV}$ [48]; $\mathrm{E}_{\mathrm{e}}$ is the energy of free electrons on the hydrogen scale (about $4.5 \mathrm{eV}$ ). Thus, the $\mathrm{E}_{\mathrm{CB}}$ and $\mathrm{E}_{\mathrm{VB}}$ of $\mathrm{WO}_{3}$ were assessed to be $+0.74 \mathrm{eV}$ and $+3.44 \mathrm{eV}$ for meso $-\mathrm{WO}_{3}$ respectively.
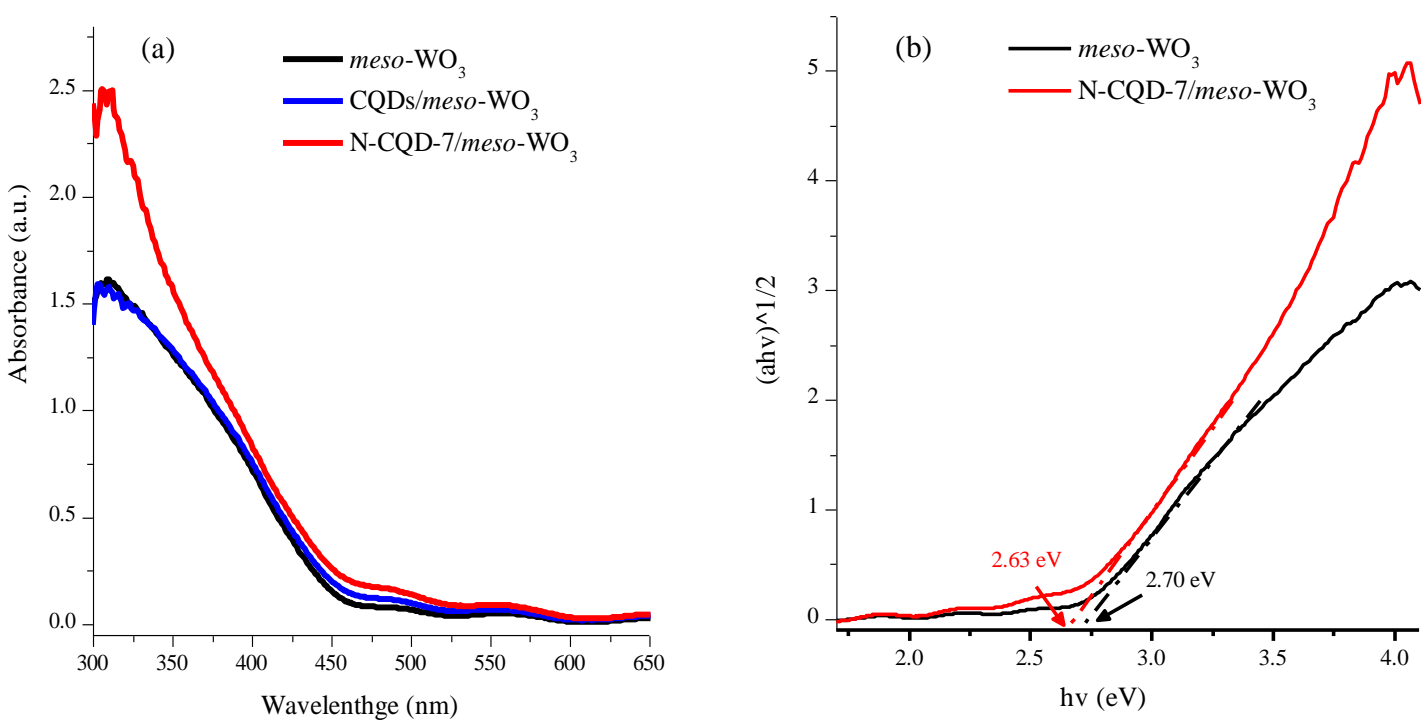

Figure 7. (a) UV-vis absorption of pristine meso- $\mathrm{WO}_{3}, \mathrm{CQDs} /$ meso- $\mathrm{WO}_{3}$, and $\mathrm{N}-\mathrm{CQDs} /$ meso- $-\mathrm{WO}_{3}$ photoanodes; (b) Tauc plots of the meso- $\mathrm{WO}_{3}$, and $\mathrm{N}-\mathrm{CQDs} /$ meso- $\mathrm{WO}_{3}$ photoanodes.

\subsection{Photo-Electrochemical Properties of the Meso- $\mathrm{WO}_{3}$ Photoanodes}

The PEC activities of the as-synthesized meso- $\mathrm{WO}_{3}, \mathrm{CQD} /$ meso- $\mathrm{WO}_{3}$, and N-CQD-7/meso- $\mathrm{WO}_{3}$ photoanodes toward water oxidation were investigated in the dark and under visible-light irradiation in a $0.5 \mathrm{M} \mathrm{Na}_{2} \mathrm{SO}_{4}$ solution ( $\mathrm{pH} \sim 6.8$ ) without adding a sacrificial agent or co-catalyst. Beforehand, the photocurrent of the meso- $\mathrm{WO}_{3}$ photoanode was optimized by varying the film thickness, which was measured by profilometer as displayed in Figure S6. Figure 8a displays the photocurrents obtained (at $1.23 \mathrm{~V}$ vs. RHE) using meso- $\mathrm{WO}_{3}$ photoanodes fabricated with various thicknesses as examined using chopped cyclic voltammograms under $100 \mathrm{~mW} \cdot \mathrm{cm}^{-2}$ visible-light excitation. As shown, the photocurrent increased from 0.21 to $0.58 \mathrm{~mA} \cdot \mathrm{cm}^{-2}$ as the thickness of the meso- $\mathrm{WO}_{3}$ film was increased from $250 \mathrm{~nm}$ to $1.42 \mu \mathrm{m}$ due to promoted light absorption, and consequently, enhanced hole-electron pair photo-generation. 

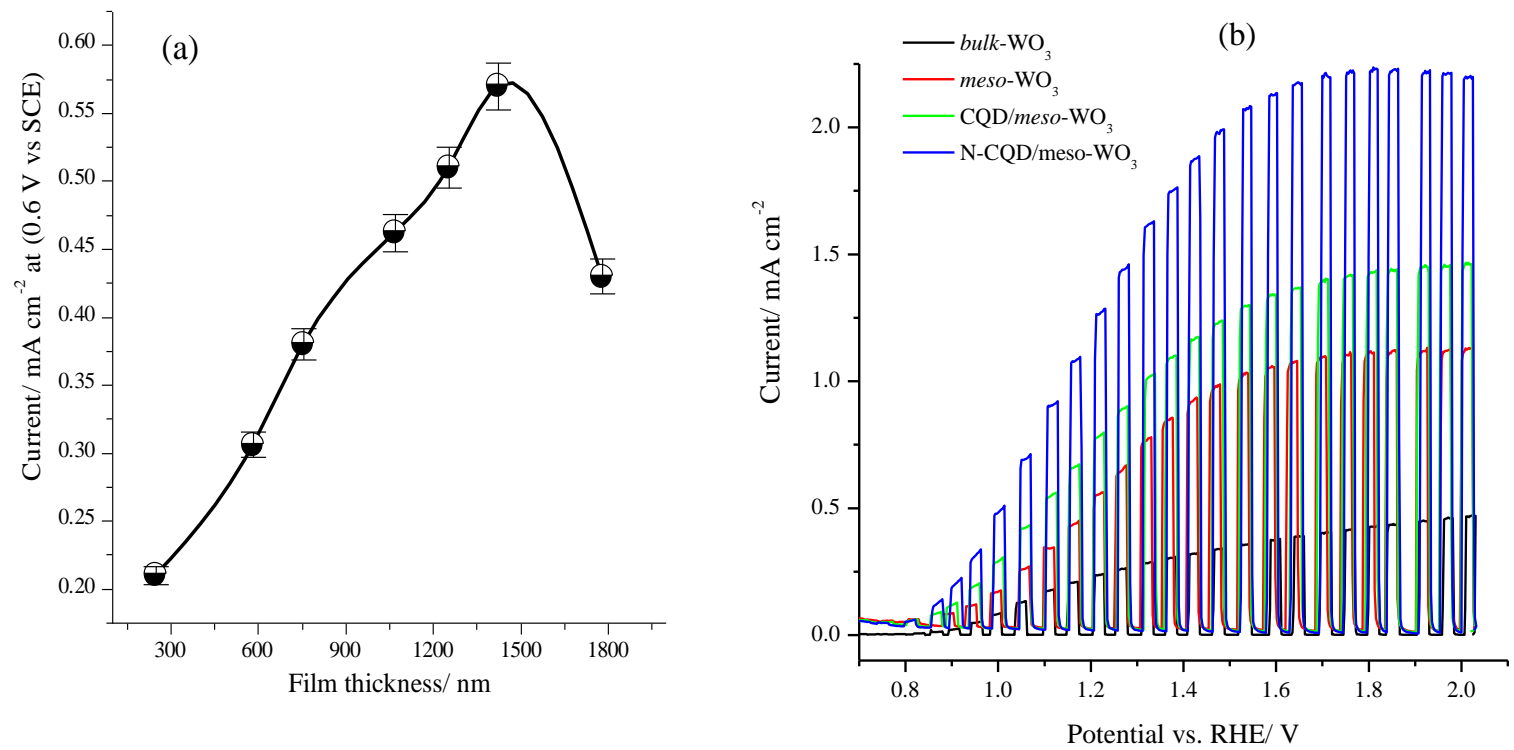

(c)

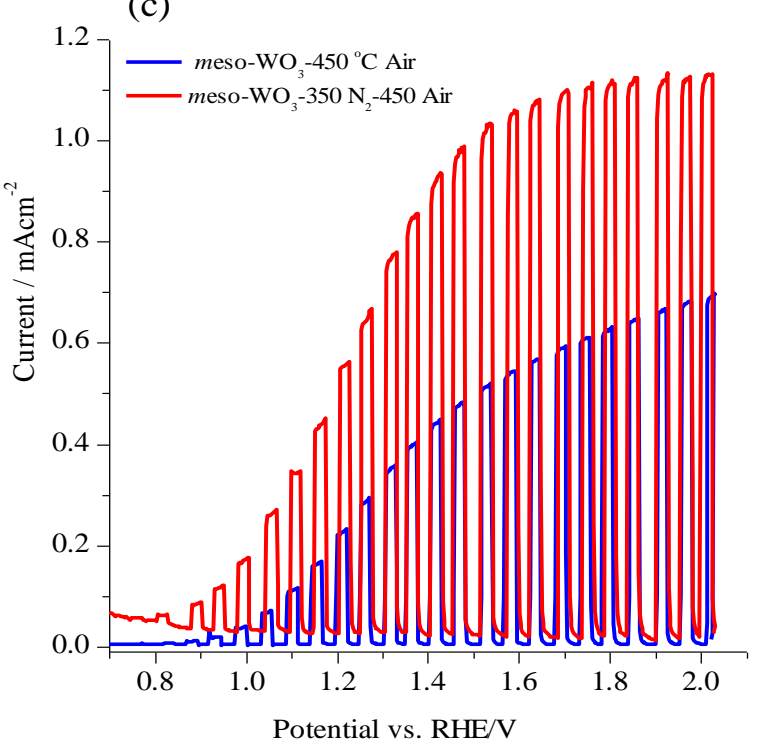

Figure 8. (a) Plot for the photocurrent obtained (at $1.23 \mathrm{~V}$ vs. RHE) using meso- $\mathrm{WO}_{3}$ photoanodes fabricated with various thicknesses, $(\mathbf{b})$ chopped cyclic voltammograms for meso- $\mathrm{WO}_{3}, \mathrm{CQDs} / \mathrm{meso}-\mathrm{WO}_{3}$, and N-CQDs/meso- $\mathrm{WO}_{3}$ in $0.5 \mathrm{M} \mathrm{Na}_{2} \mathrm{SO}_{4}$ under visible-light excitations, (c) chopped cyclic voltammograms in $0.5 \mathrm{M} \mathrm{Na}_{2} \mathrm{SO}_{4}$ under irradiation for meso- $\mathrm{WO}_{3}$ photoanodes thermally annealed at $450{ }^{\circ} \mathrm{C}$ and $350 \mathrm{~N}_{2}$ and directly annealed in air at $450{ }^{\circ} \mathrm{C}$ upon visible illumination.

However, the photocurrent decreased when the thickness of the meso- $\mathrm{WO}_{3}$ reached about $1.78 \mu \mathrm{m}$ due to an increase of the charge recombination rate. Thus, the optimum photocurrent of $0.58 \mathrm{~mA} \cdot \mathrm{cm}^{-2}$ was achieved at a film thickness of $1.42 \mu \mathrm{m}$ and $1.23 \mathrm{~V}$ vs. RHE under standard conditions. These results are comparable with those previously published for mesoporous $\mathrm{WO}_{3}$-based materials $[7,49]$. In addition to the film thickness, the surface film morphology and nanoarchitecture also influenced the PEC performance of the semiconductor photoanodes. Figure 8b shows the chopped LSVs of the bulk- $\mathrm{WO}_{3}$, meso- $\mathrm{WO}_{3}, \mathrm{CQD} /$ meso- $\mathrm{WO}_{3}$, and $\mathrm{N}-\mathrm{CQD}-7 /$ meso- $\mathrm{WO}_{3}$ photoanodes (film thickness about 1.4 $\mu \mathrm{m}$ ) at $50 \mathrm{mV} \cdot \mathrm{s}^{-1}$ under pulsed light irradiation in $0.5 \mathrm{M} \mathrm{Na}_{2} \mathrm{SO}_{4}$ solution ( $\mathrm{pH} \sim 6.8$ ). Upon illumination, the photocurrent of the photoanodes at $1.23 \mathrm{~V}$ vs. RHE decreased in the order $\mathrm{N}-\mathrm{CQD}-7 / \mathrm{meso}-\mathrm{WO}_{3}(1.45$ $\left.\mathrm{mA} \cdot \mathrm{cm}^{-2}\right)>\mathrm{CQD} /$ meso-WO$\left(0.8 \mathrm{~mA} \cdot \mathrm{cm}^{-2}\right)>$ meso-WO $\mathrm{WO}_{3}\left(0.65 \mathrm{~mA} \cdot \mathrm{cm}^{-2}\right)>$ bulk $-\mathrm{WO}_{3}\left(0.25 \mathrm{~mA} \cdot \mathrm{cm}^{-2}\right)$. 
The meso- $\mathrm{WO}_{3}$ electrode exhibited a photocurrent density of 2.6 times greater than that of its corresponding bulk- $\mathrm{WO}_{3}$ electrode, which was credited to the greater number of active sites (higher surface area) of the meso- $\mathrm{WO}_{3}$ photoanodes exposed to the electrolyte, which enhanced the PEC activity. Furthermore, the N-CQD-7/meso- $\mathrm{WO}_{3}$ photoanodes demonstrated a significantly higher photocurrent density of $1.45 \mathrm{~mA} \cdot \mathrm{cm}^{-2}$, which was 1.8 and 2.23 times greater than that of the CQDs $/$ meso- $-\mathrm{WO}_{3}$ and bare meso- $\mathrm{WO}_{3}$, respectively. Therefore, the photocurrent properties of the pristine meso- $\mathrm{WO}_{3}$ were remarkably improved by modification with N-CQDs, which suggested that the N-doped CQDs dramatically improved the charge transfer between the CQDs and the meso- $\mathrm{WO}_{3}$ thin film via electron donation from the introduced $\mathrm{N}$-atoms. As presented in Table S1, the photocurrent density of 1.45 $\mathrm{mA} \cdot \mathrm{cm}^{-2}$ at $1.23 \mathrm{~V}$ vs. RHE acquired for the N-CQD-7/meso- $\mathrm{WO}_{3}$ in our work was the highest recorded value for $\mathrm{WO}_{3}$ photoanodes decorated with carbon-based nanomaterials operating under similar conditions.

The influence of the direct annealing in air at $450{ }^{\circ} \mathrm{C}$ or in two-step annealing at $350{ }^{\circ} \mathrm{C}$ in $\mathrm{N}_{2}$ then at $450{ }^{\circ} \mathrm{C}$ in the air on the meso- $\mathrm{WO}_{3}$ photoanode $\mathrm{PEC}$ performance were investigated. Figure $8 \mathrm{c}$ shows the chopped LSVs at $50 \mathrm{mV} \cdot \mathrm{s}^{-1}$ of meso- $\mathrm{WO}_{3}$ annealed under different conditions in a $0.5 \mathrm{M}$ $\mathrm{Na}_{2} \mathrm{SO}_{4}$ solution and under pulsed light irradiation. Clearly, as shown in Figure 8c, the meso- $\mathrm{WO}_{3}$ photoanode annealed in two steps, firstly in $\mathrm{N}_{2}$ then in air exhibits an oxygen evolution potential onset potential that was approximately $100 \mathrm{mV}$ lower under light illumination, as well as a higher photocurrent density of up to $0.68 \mathrm{~mA} \cdot \mathrm{cm}^{-2}$ at $1.23 \mathrm{~V}$ vs. RHE, which was nearly two times greater than that of the $\mathrm{WO}_{3}$ photoanode treated directly in air at $450{ }^{\circ} \mathrm{C}$. This can be explained by the fact that annealing the $\mathrm{WO}_{3}$ in an $\mathrm{N}_{2}$ atmosphere first maintained the mesoporous nature of $\mathrm{WO}_{3}$ due to the presence of the residual carbon after burning the surfactant, leading to a high surface area and more active sites, and thus higher PEC performance. On the other hand, direct annealing in air destroyed the mesoporous $\mathrm{WO}_{3}$ framework, as confirmed by the SEM results in Figure 2c.

The corresponding applied bias photon-to-current efficiency (ABPE) of the meso- $\mathrm{WO}_{3}$, and $\mathrm{N}-\mathrm{CQD}-7 /$ meso- $\mathrm{WO}_{3}$ photoanodes under AM 1.5G illumination were estimated from the I-V curves via Equation (2).

$$
\operatorname{ABPE}(\%)=\left(\frac{\left[I \times\left[1.23 v-V_{b}\right]\right]}{P_{t o t}}\right) \times 100 \%
$$

where $I=$ photocurrent density at applied bias $V_{b}\left(\mathrm{~mA} / \mathrm{cm}^{2}\right), V_{b}=$ applied bias $(\mathrm{V})$, and $P_{\text {tot }}=$ power density of the incident light (AM $1.5 \mathrm{G}, 100 \mathrm{~mW} \cdot \mathrm{cm}^{-2}$ ). In particular, the efficiency of the meso $-\mathrm{WO}_{3}$ photoelectrode at $1.0 \mathrm{~V}$ vs. RHE increased from $0.07 \%$ to $0.16 \%$ when the N-CQDs were incorporated into the mesoporous structure. As mentioned earlier, the prolonged charge separation and transfer process of N-CQDs are the vital features for the promoted PEC behaviors of $\mathrm{N}-\mathrm{CQD} /$ meso- $\mathrm{WO}_{3}$ photoanode.

To obtain a better realization of the interfacial charge transfer behavior in the mesoporous modified $\mathrm{WO}_{3}$ photoanodes, an analysis of their EIS was performed. Figure 9a displays the Nyquist plots of the bare meso- $\mathrm{WO}_{3}$ and N-CQD-7/meso- $\mathrm{WO}_{3}$ electrodes at $1.23 \mathrm{~V}$ vs. RHE in the dark and under irradiation conditions.

The arc radius in the Nyquist plots indicates the charge transfer resistance at the electrode/electrolyte interface. The arc radius of the N-CQD-7/meso- $\mathrm{WO}_{3}$ electrode under both dark and light conditions was clearly smaller than those in the corresponding pristine meso- $\mathrm{WO}_{3}$ spectra, indicating faster interfacial charge transfer across the interface between the electrode and electrolyte and resulting in higher PEC performance $[33,34,50]$. In addition, the observed results evidenced that the N-doped CQDs increased the separation of charges (electrons and holes) in the $\mathrm{N}-\mathrm{CQD} /$ meso- $\mathrm{WO}_{3}$ electrode, and thus contributed to its higher PEC activity. Figure $9 \mathrm{~b}$ displays the Mott-Schottky (M-S) plots of the N-CQD/meso- $\mathrm{WO}_{3}$ and bare meso- $\mathrm{WO}_{3}$ electrodes. A positive slope was observed in the $\mathrm{M}-\mathrm{S}$ plots of bare meso- $\mathrm{WO}_{3}$ and $\mathrm{N}-\mathrm{CQD}-7 /$ meso- $\mathrm{WO}_{3}$, as expected for $\mathrm{n}$-type semiconductors. The M-S curves clearly demonstrated that the N-CQD-7/meso- $\mathrm{WO}_{3}$ electrode had a smaller slope than the pure meso- $\mathrm{WO}_{3}$ sample, indicating the increased donor density and conductivity of the former. 

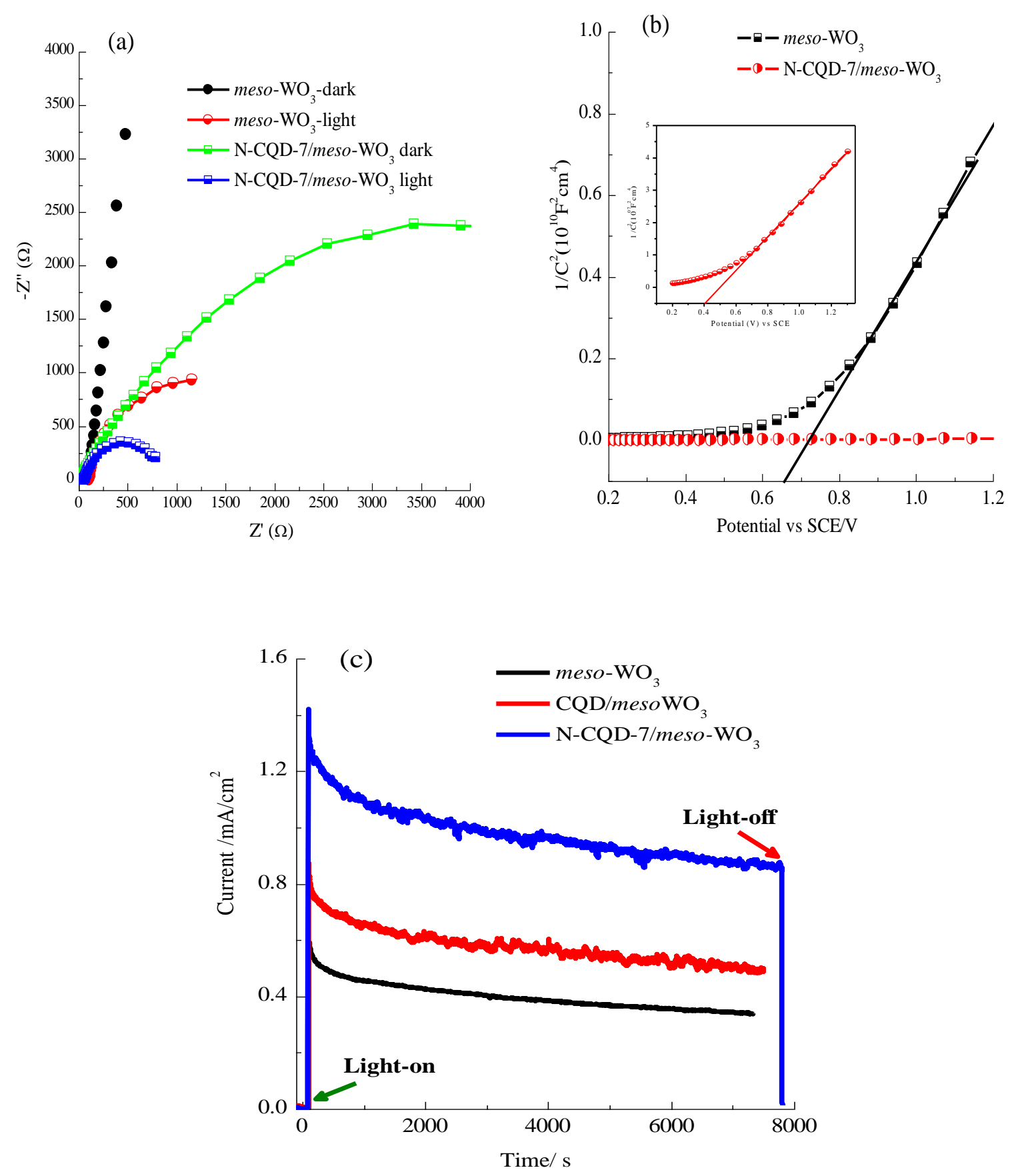

Figure 9. (a) Electrochemical impedance spectra (EIS) Nyquist-plots of pure meso- $\mathrm{WO}_{3}$ and 7-N-CQDs $/$ meso- $\mathrm{WO}_{3}$ in the dark and under the irradiation conditions of AM $1.5 \mathrm{G}$ at a bias potential of $1.0 \mathrm{~V}$ vs. SCE with an AC voltage amplitude of $20 \mathrm{mV}$; (b) Mott-Schottky plots of the bare meso- $\mathrm{WO}_{3}$ and $\mathrm{N}-\mathrm{CQDs} / \mathrm{meso}-\mathrm{WO}_{3}$ with a frequency of $1000 \mathrm{~Hz}$ in the dark and amplitude of $20 \mathrm{mV}$, (potential range $0.2-1.3 \mathrm{~V}$ ); and (c) current-time curve of the meso- $\mathrm{WO}_{3}, \mathrm{CQDs} / m e s o-\mathrm{WO}_{3}$, and 7-N-CQDs $/ m e s o-\mathrm{WO}_{3}$ composite electrode at an applied bias of $0.6 \mathrm{~V}$ vs. SCE under the illumination of AM 1.5G in $0.5 \mathrm{M}$ $\mathrm{Na}_{2} \mathrm{SO}_{4}$ solution ( $\mathrm{pH} 6.8$ ), light intensity $100 \mathrm{~mW} / \mathrm{cm}^{2}$.

The donor density of the pristine meso- $\mathrm{WO}_{3}$ and $\mathrm{N}-\mathrm{CQD} /$ meso- $\mathrm{WO}_{3}$ electrode were estimated from the slopes of the M-S curves. The calculated donor density of N-CQD-7/meso- $\mathrm{WO}_{3}$ was $2.30 \times 1021 \mathrm{~cm}^{-3}$, which was higher than that of pristine meso- $\mathrm{WO}_{3}\left(4.01 \times 1019 \mathrm{~cm}^{-3}\right)$. The improved donor density was credited to the presence of nitrogen in N-CQD, which reduced the charge recombination of hole-electron pairs and was thus credited to the superior photocurrent behavior of the N-CQD-7/meso- $\mathrm{WO}_{3}$ 
photoanode. Furthermore, by extrapolating the linear M-S curve to the potential axis as presented in Figure $9 \mathrm{~b}$, the flat band potential $\left(\mathrm{V}_{\mathrm{FB}}\right)$ of the pure meso- $\mathrm{WO}_{3}$ and $\mathrm{N}-\mathrm{CQD} /$ meso- $\mathrm{WO}_{3}$ electrodes were estimated to be 0.658 and $0.405 \mathrm{~V}$ vs. SCE, correspondingly. The $\mathrm{V}_{\mathrm{FB}}$ of $\mathrm{N}-\mathrm{CQD} /$ meso- $-\mathrm{WO}_{3}$ was more negatively shifted and smaller than that of pure meso- $\mathrm{WO}_{3}$, which matched the cathodic shift of the oxygen evolution reaction overpotential. The obvious negative shift of $\mathrm{V}_{\mathrm{FB}}$ in $\mathrm{N}-\mathrm{CQD} /$ meso- $\mathrm{WO}_{3}$ enhanced the band bending at the interface of the $\mathrm{N}-\mathrm{CQD} /$ meso $-\mathrm{WO}_{3}$ and electrolyte, thereby decreasing the recombination of the photoinduced charge-carriers and the overpotential in the oxygen evolution reaction (OER) kinetics of the $\mathrm{N}-\mathrm{CQD} /$ meso- $\mathrm{WO}_{3}$ photoelectrode [51].

Finally, the durability of the meso- $\mathrm{WO}_{3}, \mathrm{CQD} /$ meso- $\mathrm{WO}_{3}$, and N-CQD-7/meso- $\mathrm{WO}_{3}$ photoanodes was investigated using chronoamperometry in an $0.5 \mathrm{M} \mathrm{Na}_{2} \mathrm{SO}_{4}$ solution at an applied voltage of 0.6 $\mathrm{V}$ vs. SCE under AM 1.5G illumination, as displayed in Figure 9c. The photocurrent-time profile of $\mathrm{N}-\mathrm{CQD}-7 /$ meso- $\mathrm{WO}_{3}$ exhibited better stability than that of bare $m e s o-\mathrm{WO}_{3}$, with $65.6 \%$ of its initial performance being maintained ( $\left.0.88 \mathrm{vs} .1 .34 \mathrm{~mA} \cdot \mathrm{cm}^{-2}\right)$ after $2 \mathrm{~h}$ of testing. This demonstrated the role of the N-CQDs in improving the stability of the meso- $\mathrm{WO}_{3}$ by reducing the charge-carrier recombination process or by the rapid and complete OER reaction [52,53].

Figure 10 shows a proposed PEC water-splitting mechanism for the enhanced performance of the present N-CQD-7/meso- $\mathrm{WO}_{3}$ photoanodes. According to molecular orbitals (MOs) theory, various electronic transitions in N-CQD can be triggered the HOMO-LUMO (highest occupied molecular orbital, lowest unoccupied molecular orbital) energy levels under excitation of visible light [38,54], which results in a beneficial energy gap. Based on the linear potential scan method, the HOMO and LUMO positions of the N-CQD were assessed to be $\approx-0.27$ and $2.14 \mathrm{eV}$ (Figure 10), correspondingly. Moreover, the bandgap energy of N-CQDs of the electron transition obtained from the potential scans was $2.41 \mathrm{eV}$, which is consistent with earlier reports [55]. Besides, on the basis of Butler and Ginley's method, [56] the $\mathrm{VB}$ and $\mathrm{CB}$ energy levels of meso- $\mathrm{WO}_{3}$ were assessed to be 0.74 and $3.44 \mathrm{eV}$ vs. RHE, respectively. In addition, considering that the HUMO potential of N-CQDs was more positive than its corresponding $\mathrm{VB}$ potential of meso- $\mathrm{WO}_{3}$, the photoexcited holes from $\mathrm{VB}$ of meso- $\mathrm{WO}_{3}$ can instinctively transfer to the HUMO of N-CQDs. Simultaneously, the photoexcited electrons can also be transferred from $\mathrm{N}-\mathrm{CQD}$ s to meso- $\mathrm{WO}_{3}$. Hence, photoexcited electrons-holes were efficiently separated and the lifetime of the charge carriers was considerably continued. Lastly, the prolonging charge-carrier separation and transfer process can be credited to the enriched PEC response as argued earlier.

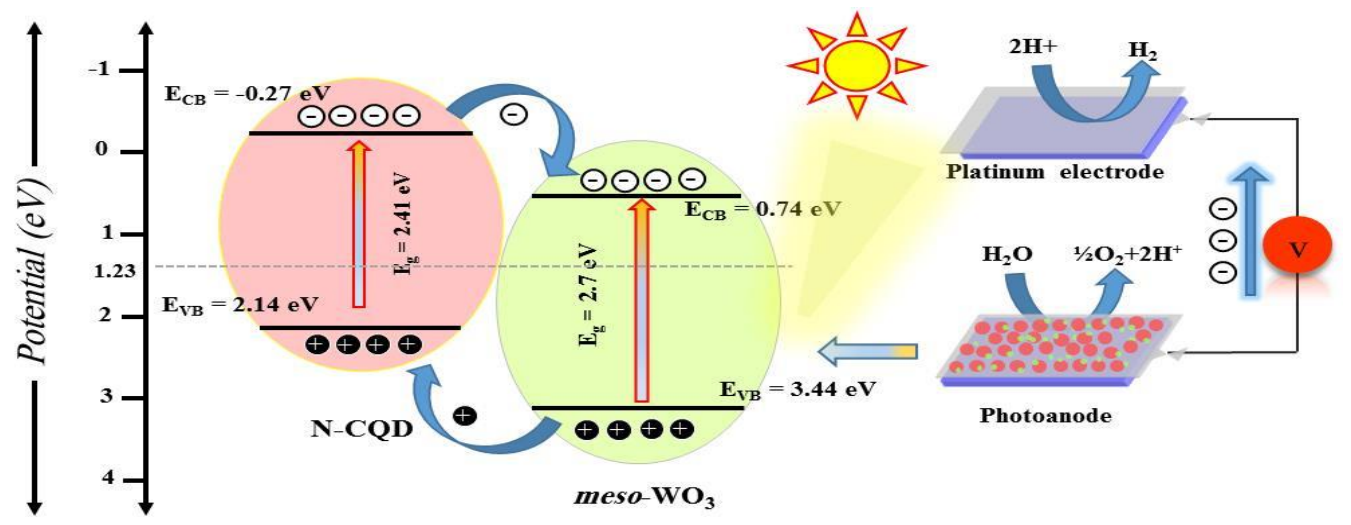

Figure 10. Proposed schematic energy-level diagram and charge migration process of N-CQDs/meso$\mathrm{WO}_{3}$ system for the photo-electrochemical (PEC) water oxidation.

\section{Conclusions}

In summary, we productively synthesized a tungsten trioxide $\mathrm{WO}_{3}$ mesoporous electrode via surfactant self-assembly and dip-coating methodologies using a high molecular-weight PEO-b-PS copolymer as a structure-directing template. This was followed by the incorporation of N-CQDs within the ordered mesostructure through impregnation assembly. Importantly, the resulting 
$\mathrm{N}-\mathrm{CQD} /$ meso- $\mathrm{WO}_{3}$ nanocomposites revealed considerably promoted PEC performance, with greater photocurrent densities $\left(1.45 \mathrm{~mA} \cdot \mathrm{cm}^{-2}\right.$ at $1.23 \mathrm{~V}$ vs. RHE) and low onset potentials (negatively shifted by $94 \mathrm{mV}$ ) compared to those of pristine meso- $\mathrm{WO}_{3}$. Furthermore, the $\mathrm{N}-\mathrm{CQD} /$ meso- $\mathrm{WO}_{3}$ photoanode demonstrated a high ABPE of $0.16 \%$ at $1.0 \mathrm{~V}$ vs. RHE. These results highlighted the multifunctional role of the hybridization of mesoporous $\mathrm{WO}_{3}$ with $\mathrm{N}$-doped CQDs in the enhancement of PEC solar water splitting.

Supplementary Materials: The following are available online at http:/www.mdpi.com/2079-4991/9/10/1502/s1, Figure S1: FTIR spectra of CQDs and N-CQDs samples, Figure S2: (a) XPS survey spectra for the CQDs, N-CQD-7 and N-CQD-20 samples. The only elements identified were carbon, nitrogen, and oxygen. (c) C 1s, (d) N 1s and (E) $\mathrm{O}$ 1s high resolution XPS spectra for N-CQD-7 sample, Figure S3: EDX spectra of N-CQDs samples, (a) N-CQD-3, (b) N-CQD-5, (c) N-CQD-7, and (d) N-CQD-20, Figure S4: (a) UV-Vis absorption spectra for the CQDs and $\mathrm{N}$-CQDs samples. Inserts show digital photos of aqueous N-CQD-7 (left) and their bright blue PL (right) under UV, $(b, c, d)$ PL spectra for the N-CQD-7, N-CQD-13, and N-CQD-20. The excitation wavelength was increased from 340 to $540 \mathrm{~nm}$ in $20 \mathrm{~nm}$ increments. (e) EQYs for the N-CQDs samples under $360 \mathrm{~nm}$ excitation, calibrated against quinine sulfate, Figure S5: steps for the synthesis of meso- $\mathrm{WO}_{3}$ and modification with CQDs, Figure S6: Thickness of meso- $\mathrm{WO}_{3}$ and modification with CQDs as measured by a profilometer, Table S1: a comparison the photocurrent density of $\mathrm{WO}_{3}$ based composite materials.

Author Contributions: M.S.A. executed the experimental part and prepared the original draft; P.A. performed and analyzes the ISE part; S.P. executed the experimental part of the carbon quantum dots characterizations, analyze and wrote the results part; M.N.A. performed the XPS analysis part and A.M.A.-M. provided the fund, resources and supervises the overall research project. Finally, M.A.G. draws the conceptualization plan, analysis and validated the results, wrote, editing and submitted the manuscript in the final form.

Funding: This research was funded by King Saud University, the Vice Deanship of Scientific Research Chairs.

Acknowledgments: The authors are grateful to the Deanship of Scientific Research, King Saud University for funding through the Vice Deanship of Scientific Research Chairs and thank the Researchers Support \& Services Unit (RSSU) for the manuscript proofreading.

Conflicts of Interest: The authors declare no conflict of interest.

\section{References}

1. Sivula, K.; Van De Krol, R. Semiconducting materials for photoelectrochemical energy conversion. Nat. Rev. Mater. 2016, 1, 15010. [CrossRef]

2. Seitz, L.C.; Chen, Z.; Forman, A.J.; Pinaud, B.A.; Benck, J.D.; Jaramillo, T.F. Modeling practical performance limits of photoelectrochemical water splitting based on the current state of materials research. ChemSusChem 2014, 7, 1372-1385. [CrossRef]

3. Cummings, C.Y.; Marken, F.; Peter, L.M.; Wijayantha, K.G.U.; Tahir, A.A. Study by Modulated Transmittance and Impedance Spectroscopies. J. Am. Chem. Soc. 2012, 134, 1228-1234. [CrossRef]

4. Wang, G.; Wang, H.; Ling, Y.; Tang, Y.; Yang, X.; Fitzmorris, R.C.; Wang, C.; Zhang, J.Z.; Li, Y. Hydrogen-treated $\mathrm{TiO}_{2}$ nanowire arrays for photoelectrochemical water splitting. Nano Lett. 2011, 11, 3026-3033. [CrossRef]

5. Yang, Q.; Wang, W.; Xu, S.; Wang, Z.L. Enhancing light emission of $\mathrm{ZnO}$ microwire-based diodes by piezo-phototronic effect. Nano Lett. 2011, 11, 4012-4017. [CrossRef]

6. Kim, T.W.; Ping, Y.; Galli, G.A.; Choi, K.S. Simultaneous enhancements in photon absorption and charge transport of bismuth vanadate photoanodes for solar water splitting. Nat. Commun. 2015, 6, 8769. [CrossRef]

7. Kim, J.K.; Shin, K.; Cho, S.M.; Lee, T.W.; Park, J.H. Synthesis of transparent mesoporous tungsten trioxide films with enhanced photoelectrochemical response: Application to unassisted solar water splitting. Energy Environ. Sci. 2011, 4, 1465-1470. [CrossRef]

8. Chandra, D.; Saito, K.; Yui, T.; Yagi, M. Crystallization of tungsten trioxide having small mesopores: Highly efficient photoanode for visible-light-driven water oxidation. Angew. Chem. Int. Ed. 2013, 52, 12606-12609. [CrossRef]

9. Hartmann, P.; Lee, D.K.; Smarsly, B.M.; Janek, J. Mesoporous $\mathrm{TiO}_{2}$ : Comparison of classical sol-gel and nanoparticle based photoelectrodes for the water splitting reaction. ACS Nano 2010, 4, 3147-3154. [CrossRef]

10. Santato, C.; Odziemkowski, M.; Ulmann, M.; Augustynski, J. Crystallographically oriented mesoporous $\mathrm{WO}_{3}$ films: Synthesis, characterization, and applications. J. Am. Chem. Soc. 2001, 123, 10639-10649. [CrossRef]

11. Liu, Y.; Koep, E.; Liu, M. A highly sensitive and fast-responding $\mathrm{SnO}_{2}$ sensor fabricated by combustion chemical vapor deposition. Chem. Mater. 2005, 17, 3997-4000. [CrossRef] 
12. Liu, J.; Gao, Y.; Wu, X.; Jin, G.; Zhai, Z.; Liu, H. Inhomogeneous oxygen vacancy distribution in semiconductor gas sensors: Formation, migration and determination on gas sensing characteristics. Sensors 2017, 17, 1852. [CrossRef]

13. Tian, B.; Liu, X.; Solovyov, L.A.; Liu, Z.; Yang, H.; Zhang, Z.; Xie, S.; Zhang, F.; Tu, B.; Yu, C.; et al. Facile Synthesis and Characterization of Novel Mesoporous and Mesorelief Oxides with Gyroidal Structures. J. Am. Chem. Soc. 2004, 126, 865-875. [CrossRef]

14. Deng, X.; Chen, K.; Tüysüz, H. Protocol for the Nanocasting Method: Preparation of Ordered Mesoporous Metal Oxides. Chem. Mater. 2017, 29, 40-52. [CrossRef]

15. Jo, C.; Hwang, J.; Song, H.; Dao, A.H.; Kim, Y.T.; Lee, S.H.; Hong, S.W.; Yoon, S.; Lee, J. Block-copolymer-assisted one-pot synthesis of ordered mesoporous $\mathrm{WO}_{3}-\mathrm{x} /$ carbon nanocomposites as high-rate-performance electrodes for pseudocapacitors. Adv. Funct. Mater. 2013, 23, 3747-3754. [CrossRef]

16. Yang, P.; Zhao, D.; Margolese, D.I.; Chmelka, B.F.; Stucky, G.D. Generalized syntheses of large-pore mesoporous metal oxides with semicrystalline frameworks. Nature 1998, 396, 152-155. [CrossRef]

17. Zhou, W.; Li, W.; Wang, J.Q.; Qu, Y.; Yang, Y.; Xie, Y.; Zhang, K.; Wang, L.; Fu, H.; Zhao, D. Ordered mesoporous black $\mathrm{TiO} 2$ as highly efficient hydrogen evolution photocatalyst. J. Am. Chem. Soc. 2014, 136, 9280-9283. [CrossRef]

18. Cheng, W.; Baudrin, E.; Dunn, B.; Zink, J.I. Synthesis and electrochromic properties of mesoporous tungsten oxide. J. Mater. Chem. 2001, 11, 92-97. [CrossRef]

19. Walcarius, A. Mesoporous materials and electrochemistry. Chem. Soc. Rev. 2013, 42, 4098-4140. [CrossRef]

20. Linares, N.; Silvestre-Albero, A.M.; Serrano, E.; Silvestre-Albero, J.; García-Martínez, J. Mesoporous materials for clean energy technologies. Chem. Soc. Rev. 2014, 43, 7681-7717. [CrossRef]

21. Ye, Y.; Jo, C.; Jeong, I.; Lee, J. Functional mesoporous materials for energy applications: Solar cells, fuel cells, and batteries. Nanoscale 2013, 5, 4584-4605. [CrossRef] [PubMed]

22. Wei, J.; Sun, Z.; Luo, W.; Li, Y.; Elzatahry, A.A.; Al-Enizi, A.M.; Deng, Y.; Zhao, D. New insight into the synthesis of large-pore ordered mesoporous materials. J. Am. Chem. Soc. 2017, 139, 1706-1713. [CrossRef] [PubMed]

23. Li, Y.; Luo, W.; Qin, N.; Dong, J.; Wei, J.; Li, W.; Feng, S.; Chen, J.; Xu, J.; Elzatahry, A.A.; et al. Highly ordered mesoporous tungsten oxides with a large pore size and crystalline framework for $\mathrm{H}_{2} \mathrm{~S}$ sensing. Angew. Chem. Int. Ed. 2014, 53, 9035-9040. [CrossRef] [PubMed]

24. Zhu, Y.; Zhao, Y.; Ma, J.; Cheng, X.; Xie, J.; Xu, P.; Liu, H.; Liu, H.; Zhang, H.; Wu, M.; et al. Mesoporous Tungsten Oxides with Crystalline Framework for Highly Sensitive and Selective Detection of Foodborne Pathogens. J. Am. Chem. Soc. 2017, 139, 10365-10373. [CrossRef] [PubMed]

25. Arunachalam, P.; Amer, M.S.; Ghanem, M.A.; Al-Mayouf, A.M.; Zhao, D. Activation effect of silver nanoparticles on the photoelectrochemical performance of mesoporous $\mathrm{TiO}_{2}$ nanospheres photoanodes for water oxidation reaction. Int. J. Hydrog. Energy 2017, 42, 11346-11355. [CrossRef]

26. Hu, D.; Diao, P.; Xu, D.; Wu, Q. Gold/ $/ \mathrm{WO}_{3}$ nanocomposite photoanodes for plasmonic solar water splitting. Nano Res. 2016, 9, 1735-1751. [CrossRef]

27. Ghanem, M.A.; Arunachalam, P.; Amer, M.S.; Al-Mayouf, A.M. Mesoporous titanium dioxide photoanodes decorated with gold nanoparticles for boosting the photoelectrochemical alkali water oxidation. Mater. Chem. Phys. 2018, 213, 56-66. [CrossRef]

28. Zhang, L.J.; Li, S.; Liu, B.K.; Wang, D.J.; Xie, T.F. Highly efficient CdS/ $\mathrm{WO}_{3}$ photocatalysts: Z-scheme photocatalytic mechanism for their enhanced photocatalytic $\mathrm{H} 2$ evolution under visible light. ACS Catal. 2014, 4, 3724-3729. [CrossRef]

29. Wang, Y.; Tian, W.; Chen, L.; Cao, F.; Guo, J.; Li, L. Three-Dimensional $\mathrm{WO}_{3}$ Nanoplate/Bi ${ }_{2} \mathrm{~S}_{3} \mathrm{Nanorod}$ Heterojunction as a Highly Efficient Photoanode for Improved Photoelectrochemical Water Splitting. ACS Appl. Mater. Interfaces 2017, 9, 40235-40243. [CrossRef]

30. Lee, Y.L.; Huang, B.M.; Chien, H.T. Highly efficient CdSe-sensitized $\mathrm{TiO}_{2}$ photoelectrode for quantum-dot-sensitized solar cell applications. Chem. Mater. 2008, 20, 6903-6905. [CrossRef]

31. Nozik, A.J. Quantum Dot Solar Cells. Phys. E Low Dimens. Syst. Nanostructures 2002, 14, 115-120. [CrossRef]

32. Li, H.; He, X.; Kang, Z.; Huang, H.; Liu, Y.; Liu, J.; Lian, S.; Tsang, C.H.A.; Yang, X.; Lee, S.T. Water-soluble fluorescent carbon quantum dots and photocatalyst design. Angew. Chem. Int. Ed. 2010, 49, 4430-4434. [CrossRef] [PubMed] 
33. Shi, W.; Lv, X.; Shen, Y. BiOI/ $\mathrm{WO}_{3}$ photoanode with enhanced photoelectrochemical water splitting activity. Front. Optoelectron. 2018, 11, 367-374. [CrossRef]

34. Zhao, Z.; Butburee, T.; Peerakiatkhajohn, P.; Lyu, M.; Wang, S.; Wang, L.; Zheng, H. Carbon Quantum Dots sensitized Vertical $\mathrm{WO}_{3}$ Nanoplates with Enhanced Photoelectrochemical Properties. ChemistrySelect 2016, 1 , 2772-2777. [CrossRef]

35. Miao, R.; Luo, Z.; Zhong, W.; Chen, S.Y.; Jiang, T.; Dutta, B.; Nasr, Y.; Zhang, Y.; Suib, S.L. Mesoporous TiO2 modified with carbon quantum dots as a high-performance visible light photocatalyst. Appl. Catal. B Environ. 2016, 189, 26-38. [CrossRef]

36. Sk, M.A.; Ananthanarayanan, A.; Huang, L.; Lim, K.H.; Chen, P. Revealing the tunable photoluminescence properties of graphene quantum dots. J. Mater. Chem. C 2014, 2, 6954-6960. [CrossRef]

37. Kong, B.; Tang, J.; Zhang, Y.; Jiang, T.; Gong, X.; Peng, C.; Wei, J.; Yang, J.; Wang, Y.; Wang, X.; et al. Incorporation of well-dispersed sub-5-nm graphitic pencil nanodots into ordered mesoporous frameworks. Nat. Chem. 2016, 8, 171-177. [CrossRef]

38. Yeh, T.F.; Teng, C.Y.; Chen, S.J.; Teng, H. Nitrogen-doped graphene oxide quantum dots as photocatalysts for overall water-splitting under visible light illumination. Adv. Mater. 2014, 26, 3297-3303. [CrossRef]

39. Arcudi, F.; Dordevic, L.; Prato, M. Synthesis, separation, and characterization of small and highly fluorescent nitrogen-doped carbon nanodots. Angew. Chem. Int. Ed. 2016, 55, 2107-2112. [CrossRef]

40. Silverstein, R.M.; Webster, F.X.; Kiemle, D.J.; Bryce, D.L. Infrared Spectroscopy. In Spectrometric Identification of Organic Compounds, 8th ed.; Wiley: Hoboken, NJ, USA, 2014; pp. 71-125.

41. Hsu, P.C.; Chang, H.T. Synthesis of high-quality carbon nanodots from hydrophilic compounds: Role of functional groups. Chem. Commun. 2012, 48, 3984-3986. [CrossRef]

42. Shi, R.; Li, Z.; Yu, H.; Shang, L.; Zhou, C.; Waterhouse, G.I.N.; Wu, L.Z.; Zhang, T. Effect of Nitrogen Doping Level on the Performance of N-Doped Carbon Quantum Dot/ $/ \mathrm{TiO}_{2}$ Composites for Photocatalytic Hydrogen Evolution. ChemSusChem 2017, 10, 4650-4656. [CrossRef] [PubMed]

43. Liu, S.; Tian, J.; Wang, L.; Zhang, Y.; Qin, X.; Luo, Y.; Asiri, A.M.; Al-Youbi, A.O.; Sun, X. Hydrothermal treatment of grass: A low-cost, green route to nitrogen-doped, carbon-rich, photoluminescent polymer nanodots as an effective fluorescent sensing platform for label-free detection of $\mathrm{Cu}(\mathrm{II})$ ions. Adv. Mater. 2012, 24, 2037-2041. [CrossRef] [PubMed]

44. Zhu, S.; Zhang, J.; Tang, S.; Qiao, C.; Wang, L.; Wang, H.; Liu, X.; Li, B.; Li, Y.; Yu, W.; et al. Surface chemistry routes to modulate the photoluminescence of graphene quantum dots: From fluorescence mechanism to up-conversion bioimaging applications. Adv. Funct. Mater. 2012, 22, 4732-4740. [CrossRef]

45. Long, B.; Huang, Y.; Li, H.; Zhao, F.; Rui, Z.; Liu, Z.; Tong, Y.; Ji, H. Carbon Dots Sensitized BiOI with Dominant $\{001\}$ Facets for Superior Photocatalytic Performance. Ind. Eng. Chem. Res. 2015, 54, 12788-12794. [CrossRef]

46. Tang, C.; Liu, E.; Wan, J.; Hu, X.; Fan, J. $\mathrm{Co}_{3} \mathrm{O}_{4}$ nanoparticles decorated $\mathrm{Ag}_{3} \mathrm{PO}_{4}$ tetrapods as an efficient visible-light-driven heterojunction photocatalyst. Appl. Catal. B Environ. 2016, 181, 707-715. [CrossRef]

47. Wang, Y.; Zhang, X.; Liu, J.; Wang, Y.; Duan, D.; Fan, C. Facile regeneration and photocatalytic activity of CuO-modified silver bromide photocatalyst. Mater. Sci. Semicond. Process. 2015, 40, 613-620. [CrossRef]

48. Liu, Y.; Li, Q.; Gao, S.; Shang, J.K. Template-free solvothermal synthesis of $\mathrm{WO}_{3} / \mathrm{WO}_{3} \bullet \mathrm{H}_{2} \mathrm{O}$ hollow spheres and their enhanced photocatalytic activity from the mixture phase effect. CrystEngComm 2014, 16, 7493-7501. [CrossRef]

49. Hilliard, S.; Baldinozzi, G.; Friedrich, D.; Kressman, S.; Strub, H.; Artero, V.; Laberty-Robert, C. Mesoporous thin film $\mathrm{WO}_{3}$ photoanode for photoelectrochemical water splitting: A sol-gel dip coating approach. Sustain. Energy Fuels 2017, 1, 145-153.

50. Ye, K.H.; Wang, Z.; Gu, J.; Xiao, S.; Yuan, Y.; Zhu, Y.; Zhang, Y.; Mai, W.; Yang, S. Carbon quantum dots as a visible light sensitizer to significantly increase the solar water splitting performance of bismuth vanadate photoanodes. Energy Environ. Sci. 2017, 10, 772-779. [CrossRef]

51. Zhong, D.K.; Sun, J.; Inumaru, H.; Gamelin, D.R. Solar Water Oxidation by Composite Catalyst / $\mathrm{r}-\mathrm{Fe}_{2} \mathrm{O}_{3}$ Photoanodes. J. Am. Chem. Soc. 2009, 131, 6086-6087. [CrossRef]

52. Zhang, P.; Wang, T.; Chang, X.; Zhang, L.; Gong, J. Synergistic Cocatalytic Effect of Carbon Nanodots and $\mathrm{Co}_{3} \mathrm{O}_{4}$ Nanoclusters for the Photoelectrochemical Water Oxidation on Hematite. Angew. Chem. Int. Ed. 2016, 55, 5851-5855. [CrossRef] [PubMed] 
53. Liu, J.; Liu, Y.; Liu, N.; Han, Y.; Zhang, X.; Huang, H.; Lifshitz, Y.; Lee, S.T.; Zhong, J.; Kang, Z. Metal-free efficient photocatalyst for stable visible water splitting via a two-electron pathway. Science 2015, 347, 970-974. [CrossRef] [PubMed]

54. Tang, L.; Ji, R.; Li, X.; Teng, K.S.; Lau, S.P. Energy-level structure of nitrogen-doped graphene quantum dots. J. Mater. Chem. C 2013, 1, 4908-4915. [CrossRef]

55. Kong, W.; Zhang, X.; Liu, S.; Zhou, Y.; Chang, B.; Zhang, S.; Fan, H.; Yang, B. N Doped Carbon Dot Modified $\mathrm{WO}_{3}$ Nanoflakes for Efficient Photoelectrochemical Water Oxidation. Adv. Mater. Interfaces 2019, 6, 1801653. [CrossRef]

56. Butler, M.A.; Ginley, D.S. Prediction of Flat band Potentials at Semiconductor-Electrolyte Interfaces from Atomic Electronegativities. J. Electrochem. Soc. 1978, 125, 228-232. [CrossRef]

(C) 2019 by the authors. Licensee MDPI, Basel, Switzerland. This article is an open access article distributed under the terms and conditions of the Creative Commons Attribution (CC BY) license (http://creativecommons.org/licenses/by/4.0/). 